\title{
Organo-soluble and Lightly-colored Fluorinated Polyimides Based on 2,2-Bis[4-(3,4-dicarboxyphenoxy)phenyl]hexafluoropropane Dianhydride and Aromatic Bis(ether amine)s Bearing Pendent Trifluoromethyl Groups
}

\author{
Chin-Ping YANG, ${ }^{\dagger}$ Yu-Yang Su, and Mei-Yuan Hsu \\ Department of Chemical Engineering, Tatung University, \\ 40 Chungshan North Road, 3rd Section, Taipei 104, Taiwan
}

(Received August 31, 2005; Accepted October 4, 2005; Published February 15, 2006)

\begin{abstract}
Two series of soluble and light-colored poly(ether imide)s (III and IV) were synthesized from 2,2bis[4-(3,4-dicarboxyphenoxyl)phenyl]hexafluoropropane dianhydride (I) and various fluorinated and non-fluorinated aromatic diamines $\left(\mathbf{I I}_{\mathbf{a}-\mathbf{g}}\right.$ and $\mathbf{I I}_{\mathbf{a}-\mathbf{g}}$ ) by a conventional two-step procedure that included a ring-opening polyaddition to give poly(amic acid)s, followed by chemical cyclodehydration to poly(ether imide)s. The III series were lighter-colored and higher optical transparency as compared with the non-fluorinated IV series. On comparing the IV series with the common lightly-colored aromatic polyimides ( $\mathbf{V}$ series) based on 2,2-bis(3,4-dicarboxyphenyl)hexafluoropropane dianhydride (6FDA), the IV series revealed less colored than the $\mathbf{V}$ series. This indicated that both the III and IV series were lightly-colored poly(ether imide)s. These polymer films showed the cutoff wavelength in the range of 364$371 \mathrm{~nm}$. The III series showed good solubility in all testing solvents at a concentration of $5-10 \mathrm{wt} / \mathrm{v} \%$ and most of IV series was soluble. These polymers exhibited glass-transition temperatures in the range of $194-264{ }^{\circ} \mathrm{C}$, and the $10 \%$ weight-loss temperatures were higher than $492{ }^{\circ} \mathrm{C}$ under either nitrogen or air atmosphere. The III series also showed lower dielectric constants of 3.01-3.65 at $1 \mathrm{MHz}$ and lower moisture absorption of $0.09-0.44 \mathrm{wt} \%$ than IV series. [DOI 10.1295/polymj.38.132]

KEY WORDS 2,2-Bis[4-(3,4-dicarboxyphenoxy)phenyl]hexafluoropropane Dianhydride / Fluorinated Poly(ether imide) / Light Color Polyimide / Organo-solube Polyimide / Bis(ether anhydride) /
\end{abstract}

Aromatic polyimides are widely used in the aerospace and electronic industries in the form of films and moldings because of high performance for their excellent thermal stabilities, chemical resistance, and electric properties. ${ }^{1,2}$ Optical transparency of polyimide films is of special importance in some application such as orientation films in liquid crystal display devices, ${ }^{3}$ and optical half-waveplates for planar lightwave circuits. ${ }^{4}$ However, most polyimides between UV and the visible area have strong absorption, rendering their color close to yellow or brown. In addition, they have poor processability in their imidized forms because of high softening temperatures and insolubility.

By introducing the ether chain ${ }^{5,6}$ or bulky group, ${ }^{7,8}$ the aromatic polyimide can raise the flexibility of polymer, reduce the melting point or $T_{\mathrm{g}}$, and improve solubility. It was also proved that a lowering of the formation of the charge-transfer complex (CTC) between alternating electron-donor (diamine) and electron-acceptor (dianhydride) moieties provides polyimide with lighter color. ${ }^{9,10}$ Among the six kinds of commercially available aromatic dianhydrides including pyromellitic dianhydride (PMDA), 3,3',4,4'-benzophenone-tetra- carboxylic dianhydride (BTDA), 3,3',4,4'-biphenyltetracarboxylic dianhydride (BPDA), diphenylsulfone-3,3',4,4'-tetracarboxylic dianhydride (DSDA), 4,4'-oxydiphthalic dianhydride (ODPA) and 6FDA, the polyimides were deriving from ODPA or 6FDA with aromatic diamines showed lighter color than others. The reason was proposed that polyimides containing ether chains ${ }^{11-13}$ or hexafluoroisopropylidene group ${ }^{9,14}$ could reduce the CTC formation of polymer. Therefore, we synthesized the bis(ether anhydride) containing ether chains and hexafluoroisopropylidene group, 2,2-bis[4-(3,4-dicarboxyphenoxy)phenyl]hexafluoropropane dianhydride (I), and produced a series of lightly-colored poly(ether imide) films with various aromatic diamines. Though some poly(ether imide)s had been prepared from bis(ether anhydride) $(\mathbf{I}),{ }^{15-17}$ their color and dielectric constants etc. were less discussed. Recently, it had also been proved that polyimide contained the trifluoromethyl or ether group can enhance the solubility and thermal stability, reduce dielectric constant and moisture absorption, and raise the optical transparency. ${ }^{18-22}$

In this study, the bis(ether anhydride) I was prepared and a series of novel poly(ether imide)s (III)

${ }^{\dagger}$ To whom correspondence should be addressed (Tel: +886-2-25925252 ext.2977; Fax: +886-2-25861393. E-mail: cpyang@ttu.edu.tw). 
were prepared from $\mathbf{I}$ with $\mathrm{CF}_{3}$-contained diamines $\mathbf{I I}_{\mathbf{a}-\mathbf{g}}$. These polymers were investigated in regard to their solubility, color, optical transparency, dielectric property, and moisture absorption, and they were compared to analogous non-fluorinated poly(ether imide)s IV. Moreover, these polymers were also compared with polyimide-6FDA in color.

\section{EXPERIMENTAL}

\section{Materials}

2,2-Bis(4-hydroxyphenyl)hexafluoropropane (6Fbisphenol-A; Acros), 1,4-bis(4-amino-2-trifluoromethylphenoxy)benzene (mp $\left.132-133^{\circ} \mathrm{C}, \mathbf{I I}_{\mathbf{a}}\right),{ }^{24} 1,2$-bis(4amino-2-trifluoromethylphenoxy)benzene (mp 116$\left.117^{\circ} \mathbf{C}, \mathbf{I I}_{\mathbf{b}}\right),{ }^{25}$ 4, $4^{\prime}$-bis(4-amino-2-trifluoromethylphenoxy)biphenyl (mp $\left.155-156^{\circ} \mathrm{C}, \quad \mathbf{I I}_{\mathbf{c}}\right),{ }^{12} \quad 4,4^{\prime}$-bis(4amino-2-trifluoromethylphenoxy)-3,3',5,5'-tetramethylbiphenyl (mp $256-257^{\circ} \mathrm{C}, \mathbf{I I}_{\mathbf{d}}$ ), ${ }^{26}$ 2,2-bis[4-(4-amino2-trifluoromethylphenoxy)phenyl]propane (mp 131$\left.132{ }^{\circ} \mathrm{C}, \quad \mathbf{I I}_{\mathbf{e}}\right),{ }^{27}$ 2,2-bis[4-(4-amino-2-trifluoromethylphenoxy)phenyl]hexafluoropropane $\left(\mathrm{mp} \quad 65-66^{\circ} \mathrm{C}\right.$, $\left.\mathbf{I I}_{\mathbf{f}}\right){ }^{28}$ 9,9-bis[4-(4-amino-2-trifluoromethylphenoxy)phenyl]fluorene $\left(\mathrm{mp} 239-240^{\circ} \mathrm{C}, \mathbf{I I}_{\mathrm{g}}\right),{ }^{29} \quad 4,4^{\prime}$-bis $(4-$ aminophenoxy)biphenyl (mp $\left.137-138^{\circ} \mathbf{C}, \mathbf{I I}^{\prime} \mathbf{c}\right),{ }^{30} 4,4^{\prime}$ bis(4-aminophenoxy)-3,3',5,5' -tetramethylbiphenyl (mp 227-228 $\left.{ }^{\circ} \mathbf{C}, \mathbf{I I}_{\mathbf{d}}\right)^{31}$ and 9,9-bis[4-(4-aminophenoxy)phenyl]fluorene (mp $\left.239-240{ }^{\circ} \mathbf{C}, \mathbf{I I}_{\mathbf{g}}^{\prime}\right)^{32}$ were prepared according to the literature procedures. Other aromatic diamines 1,4-bis(4-aminophenoxy)benzene $\left(\mathbf{I I}_{\mathbf{a}}^{\prime}, \mathrm{TCI}\right), 1,2^{\prime}$-bis(4-aminophenoxy)benzene $\left(\mathbf{I I}_{\mathbf{b}}^{\prime}\right.$, Chriskev), 2,2-bis[4-(4-aminophenoxy)phenyl]propane (II' ${ }_{\mathbf{e}}$, Chriskev) and 2,2-bis[4-(4-aminophenoxy)phenyl] hexafluoropropane ( $\mathbf{I I}_{\mathbf{f}}^{\prime}$, Chriskev) were used as received. Commerially available aromatic dianhydrides including PMDA (Lancaster), BTDA (Acros), and ODPA (Chriskev) were recrystallized from acetic anhydride before use. BPDA (Chriskev), DSDA (New Japan Chemical Co.), and 6FDA (Chriskev) were used as received. Others including 2-chloro-5-nitrobenzotrifluoride (Acros), $p$-chloronitrobenzene (TCI), 4-nitrophthalodinitrile (Acros), acetic anhydride $\left(\mathrm{Ac}_{2} \mathrm{O}\right.$, Fluka), $N, N$-dimethylacetamide (DMAc, Fluka) and $\mathrm{N}, \mathrm{N}$-dimethyl formamide (DMF, Fluka) were used as received.

\section{Synthesis of Monomers}

2,2-Bis[4-(3,4-dicyanophenoxy)phenyl]hexafluoropropane $\left(\boldsymbol{I}^{\prime}\right)$. 6F-bisphenol-A $(8.40 \mathrm{~g}, 25 \mathrm{mmol}), 4$ nitrophthalonitrile $(8.65 \mathrm{~g}, 50 \mathrm{mmol})$ and $\mathrm{K}_{2} \mathrm{CO}_{3}(6.90$ $\mathrm{g}, 50 \mathrm{mmol}$ ) were suspended in $50 \mathrm{~mL}$ of DMF in a 250-mL flask. The suspension solution was stirred at room temperature for $24 \mathrm{~h}$. Then, the reaction mixture was poured into $600 \mathrm{~mL}$ of water, and the precipitated white solid was collected and washed thoroughly with water, methanol and acetonitrile. The yield of the product was $14.26 \mathrm{~g}$ (97\% yield). The crude product was purified by recrystallization from acetonitrile. The yield of the purified product was $9.64 \mathrm{~g}$ (74\% yield) (mp $235^{\circ} \mathrm{C}$ [Lit..$\left.\left.^{15} 230^{\circ} \mathrm{C}\right]\right)$. IR (KBr): 2235 (CN) and $1243 \mathrm{~cm}^{-1}(\mathrm{C}-\mathrm{O}) .{ }^{1} \mathrm{H}$ NMR $(500 \mathrm{MHz}$, $\left.\mathrm{CDCl}_{3}, \delta, \mathrm{ppm}\right): 8.15\left(\mathrm{~d}, J=8.7 \mathrm{~Hz}, 2 \mathrm{H}, \mathrm{H}_{\mathrm{b}}\right), 7.94(\mathrm{~d}$, $\left.J=2.3 \mathrm{~Hz}, 2 \mathrm{H}, \mathrm{H}_{\mathrm{a}}\right), 7.54(\mathrm{dd}, J=8.7,2.3 \mathrm{~Hz}, 2 \mathrm{H}$, $\left.\mathrm{H}_{\mathrm{c}}\right), 7.50\left(\mathrm{~d}, J=8.6 \mathrm{~Hz}, 4 \mathrm{H}, \mathrm{H}_{\mathrm{e}}\right) 7.30(\mathrm{~d}, J=8.6 \mathrm{~Hz}$, $\left.4 \mathrm{H}, \mathrm{H}_{\mathrm{d}}\right) \cdot{ }^{13} \mathrm{C} \mathrm{NMR}\left(125 \mathrm{MHz}, \mathrm{CDCl}_{3}, \delta, \mathrm{ppm}\right): 159.9$ $\left(\mathrm{C}^{3}\right), 154.9\left(\mathrm{C}^{7}\right), 136.4\left(\mathrm{C}^{9}\right), 132.0\left(\mathrm{C}^{10}\right), 128.8\left(\mathrm{C}^{5}\right)$, $124.0\left(\mathrm{C}^{12}\right.$, quartet, $\left.{ }^{1} J_{\mathrm{C}-\mathrm{F}}=285 \mathrm{~Hz}\right), 123.6\left(\mathrm{C}^{4}\right), 123.1$ $\left(\mathrm{C}^{2}\right), 119.9\left(\mathrm{C}^{8}\right), 116.7\left(\mathrm{C}^{1}\right), 115.7,115.3\left(\mathrm{C}^{13,13^{\prime}}\right)$, $109.2\left(\mathrm{C}^{6}\right), 63.4\left(\mathrm{C}^{11}\right.$, septet, $\left.{ }^{2} J_{\mathrm{C}-\mathrm{F}}=25 \mathrm{~Hz}\right)$.

2,2-Bis[4-(3,4-dicarboxyphenoxy)phenyl]hexafluoropropane $\left(\boldsymbol{I}^{\prime \prime}\right)$. A suspension of bis(ether dinitrile) $\mathbf{I}^{\prime}$ $(9.40 \mathrm{~g}, 16 \mathrm{mmol})$ in an ethanol/water mixture (110 $\mathrm{mL} / 110 \mathrm{~mL})$ containing $\mathrm{KOH}(27 \mathrm{~g}, 0.48 \mathrm{~mol})$ in a 500 -mL flask was boiled under reflux at $80-100^{\circ} \mathrm{C}$. The mixture was refluxed for about $24 \mathrm{~h}$ until the evolution of ammonia had ceased. The resulting hot, clear solution was filtered to remove any possible insoluble impurities. After cooling, the filtrate was acidified by addition of concentrated $\mathrm{HCl}$ to $\mathrm{pH}=1-2$. The resulting precipitate was filtered, washed with boiling water and dried under vacuum $\left(100^{\circ} \mathrm{C}\right)(10.10 \mathrm{~g}, 96 \%$ two endothermic peaks $110-170^{\circ} \mathrm{C}$ and $233^{\circ} \mathrm{C}$, and one exothermic peak $184^{\circ} \mathrm{C}$. IR (KBr): $2500-3600(\mathrm{O}-\mathrm{H})$, $1714(\mathrm{C}=\mathrm{O})$ and $1288 \mathrm{~cm}^{-1}(\mathrm{C}-\mathrm{O}-\mathrm{C}) .{ }^{1} \mathrm{H}$ NMR $(500$ $\left.\mathrm{MHz}, \mathrm{CDCl}_{3}, \delta, \mathrm{ppm}\right): 7.86\left(\mathrm{~d}, J=8.5 \mathrm{~Hz}, 2 \mathrm{H}, \mathrm{H}_{\mathrm{b}}\right.$ ), $7.42\left(\mathrm{~d}, J=8.4 \mathrm{~Hz}, 4 \mathrm{H}, \mathrm{H}_{\mathrm{e}}\right), 7.35(\mathrm{~d}, J=2.3 \mathrm{~Hz}, 2 \mathrm{H}$, $\left.\mathrm{H}_{\mathrm{a}}\right), 7.23\left(\mathrm{dd}, J=8.5,2.3 \mathrm{~Hz}, 2 \mathrm{H}, \mathrm{H}_{\mathrm{c}}\right), 7.18(\mathrm{~d}, J=$ $\left.8.4 \mathrm{~Hz}, 4 \mathrm{H}, \mathrm{H}_{\mathrm{d}}\right) .{ }^{13} \mathrm{C} \mathrm{NMR}\left(125 \mathrm{MHz}, \mathrm{CDCl}_{3}, \delta, \mathrm{ppm}\right)$ : 168.4, $167.8\left(\mathrm{C}^{13,13^{\prime}}\right), 157.9\left(\mathrm{C}^{3}\right), 156.7\left(\mathrm{C}^{7}\right), 136.8$ $\left(\mathrm{C}^{10}\right), 132.2\left(\mathrm{C}^{1}\right), 131.9\left(\mathrm{C}^{9}\right), 127.9\left(\mathrm{C}^{5}\right), 127.8\left(\mathrm{C}^{6}\right)$, $124.2\left(\mathrm{C}^{12}\right.$, quartet, $\left.{ }^{1} J_{\mathrm{C}-\mathrm{F}}=285 \mathrm{~Hz}\right), 120.4\left(\mathrm{C}^{4}\right), 119.1$ $\left(\mathrm{C}^{8}\right), 118.8\left(\mathrm{C}^{2}\right), 63.5\left(\mathrm{C}^{11}\right.$, septet, $\left.{ }^{2} J_{\mathrm{C}-\mathrm{F}}=25 \mathrm{~Hz}\right)$.

2,2-Bis[4-(3,4-dicarboxyphenoxy)phenyl]hexafluoropropane Dianhydride (I). Bis(ether diacid) I' $(9.96 \mathrm{~g}, 15 \mathrm{mmol})$ was suspended in $30 \mathrm{~mL}$ of acetic anhydride and $30 \mathrm{~mL}$ of glacial acetic acid in a 200$\mathrm{mL}$ flask. The suspension was boiled under reflux until turning into a clear solution. During cooling, the crystallized white crystals were collected, washed with dry toluene, and dried in vacuum to give I (8.70 g, 92\%; mp $233^{\circ} \mathrm{C}$ [Lit. ${ }^{15} 228^{\circ} \mathrm{C}$ ]). IR (KBr): 1849 (asym. $\mathrm{C}=\mathrm{O}$ str.), 1781 (sym. $\mathrm{C}=\mathrm{O}$ str.) and 1288 $\mathrm{cm}^{-1}(\mathrm{C}-\mathrm{O}-\mathrm{C}) .{ }^{1} \mathrm{H}$ NMR and ${ }^{13} \mathrm{C}$ NMR of $\mathbf{I}$ were shown in Figure 2.

\section{Synthesis of Poly(ether imide)s}

Diamine $\mathbf{I I}_{\mathbf{a}}(0.213 \mathrm{~g}, 0.5 \mathrm{mmol})$ was dissolved in $4.1 \mathrm{~mL}$ dried DMAc in a $25-\mathrm{mL}$ flask. After the diamine had completely dissolved, bis(ether anhydride) I $(0.308 \mathrm{~g}, 0.5 \mathrm{mmol})$ was added in one portion. The 


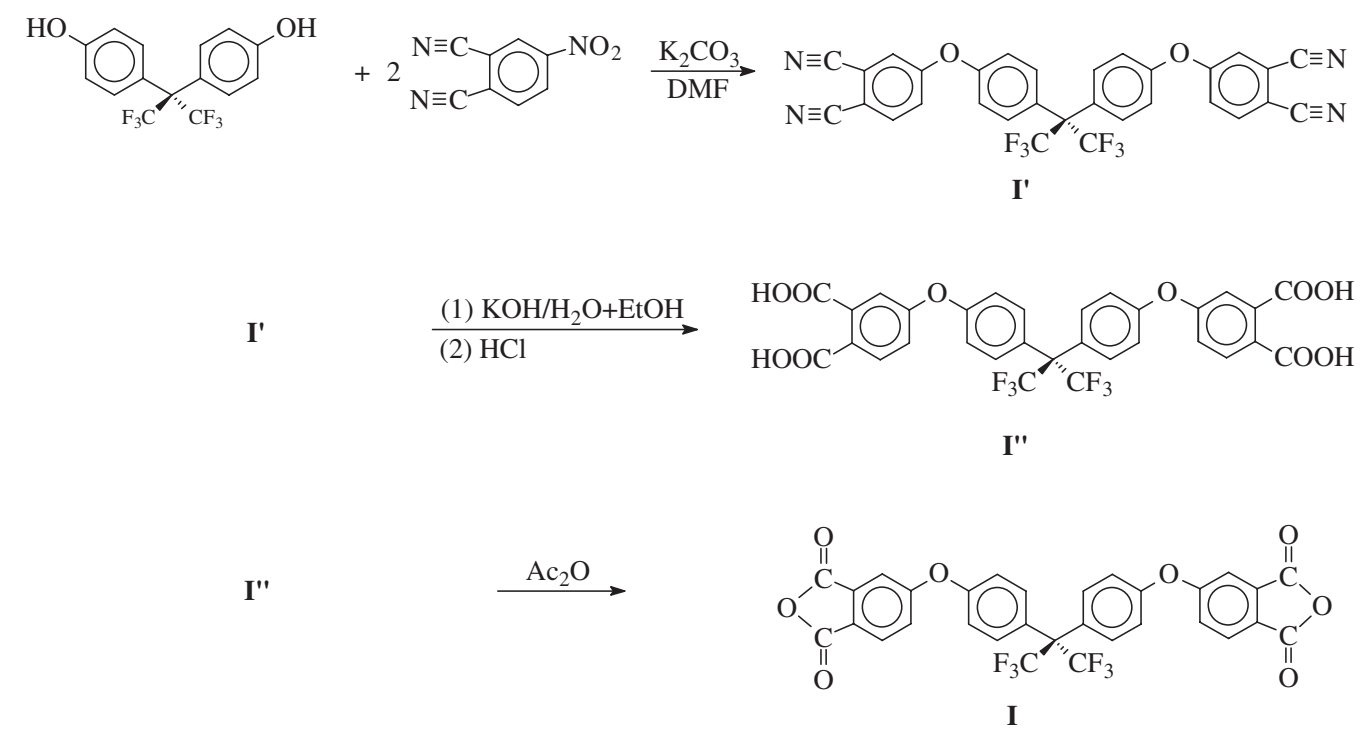

Scheme 1.

mixture was stirred at room temperature for $12 \mathrm{~h}$ to form a viscous poly(amic acid) (PAA) solution. Then a 0.5-mL mixture of $\mathrm{Ac}_{2} \mathrm{O} / \mathrm{Py}$ (volume ratio 2/1) was added to PAA solution. The mixture was stirred at $80^{\circ} \mathrm{C}$ for $1 \mathrm{~h}$, and resulting solution then was poured into a glass culture dish, which was placed in an $110^{\circ} \mathrm{C}$ oven for $1 \mathrm{~h}$ to remove solvent. The semidried polyimide film was further dried to $200^{\circ} \mathrm{C}$ gradually, and heated at $200{ }^{\circ} \mathrm{C}$ for $1 \mathrm{~h}$ to remove residual solvent. Then, the polymer film was stripped from the glass substrate by soaked in water. Inherent viscosity of III $_{\mathbf{a}}$ was $0.83 \mathrm{dL} / \mathrm{g}$ in DMAc at a $0.5 \mathrm{~g} / \mathrm{dL}$ concentration at $30{ }^{\circ} \mathrm{C}$.

IR (film): 1780, 1728, 1489, 1379, 1234, 1054, 744 $\mathrm{cm}^{-1} .{ }^{1} \mathrm{H}$ NMR $\left(500 \mathrm{MHz}, \mathrm{CDCl}_{3}, \delta, \mathrm{ppm}\right): 8.01(\mathrm{~d}$, $\left.J=7.9 \mathrm{~Hz}, 2 \mathrm{H}, \mathrm{H}_{\mathrm{b}}\right), 7.93\left(\mathrm{~s}, 2 \mathrm{H}, \mathrm{H}_{\mathrm{f}}\right), 7.72(\mathrm{~d}, J=$ $\left.8.1 \mathrm{~Hz}, 2 \mathrm{H}, \mathrm{H}_{\mathrm{g}}\right), 7.56\left(\mathrm{~s}, 2 \mathrm{H}, \mathrm{H}_{\mathrm{a}}\right), 7.53(\mathrm{~d}, J=8.5$ $\left.\mathrm{Hz}, 4 \mathrm{H}, \mathrm{H}_{\mathrm{e}}\right), 7.52\left(\mathrm{~d}, J=7.9 \mathrm{~Hz}, 2 \mathrm{H}, \mathrm{H}_{\mathrm{c}}\right), 7.29(\mathrm{~d}$, $\left.J=8.5 \mathrm{~Hz}, 4 \mathrm{H}, \mathrm{H}_{\mathrm{d}}\right), 7.27\left(\mathrm{~s}, 4 \mathrm{H}, \mathrm{H}_{\mathrm{i}}\right), 7.23(\mathrm{~d}, J=$ $\left.8.1 \mathrm{~Hz}, 2 \mathrm{H}, \mathrm{H}_{\mathrm{h}}\right) \cdot{ }^{13} \mathrm{C}$ NMR $\left(125 \mathrm{MHz}\right.$, DMSO- $d_{6}, \delta$, ppm): 166.1, $166.0\left(\mathrm{C}^{22,23}\right), 161.4\left(\mathrm{C}^{3}\right), 156.0\left(\mathrm{C}^{7}\right)$, $154.5\left(\mathrm{C}^{20}\right), 152.0\left(\mathrm{C}^{16}\right), 134.3\left(\mathrm{C}^{10}\right), 133.2\left(\mathrm{C}^{1}\right)$, $132.0\left(C^{9}\right), 128.3\left(C^{13}\right), 126.7\left(C^{5}\right), 126.3\left(C^{6}\right), 126.0$ $\left(\mathrm{C}^{18}\right), 124.0\left(\mathrm{C}^{4}\right), 123.9\left(\mathrm{C}^{12}\right.$, quartet, ${ }^{1} J_{\mathrm{C}-\mathrm{F}}=284$ $\mathrm{Hz}), 123.0\left(\mathrm{C}^{19}\right.$, quartet, $\left.{ }^{1} J_{\mathrm{C}-\mathrm{F}}=273 \mathrm{~Hz}\right), 121.9\left(\mathrm{C}^{14}\right)$, $121.6\left(\mathrm{C}^{8,17}\right), 119.7\left(\mathrm{C}^{21}\right), 119.6\left(\mathrm{C}^{15}\right.$, quartet, ${ }^{2} J_{\mathrm{C}-\mathrm{F}}=$ $31 \mathrm{~Hz}), 113.1\left(\mathrm{C}^{2}\right), 63.5\left(\mathrm{C}^{11}\right.$, septet, $\left.{ }^{2} J_{\mathrm{C}-\mathrm{F}}=25 \mathrm{~Hz}\right)$.

\section{Measurements}

IR spectra were recorded on a Horiba FourierTransform Infrared Spectrometer FT-IR-720. Elemental analyses were run in a Perkin-Elmer Model 2400 $\mathrm{CHN}$ analyzer. ${ }^{1} \mathrm{H}$ and ${ }^{13} \mathrm{C}$ spectra were recorded on a Bruker AV-500 FT-NMR spectrometer. Inherent viscosities were determined at a $0.5 \mathrm{~g} / \mathrm{dL}$ concentration using a Cannon-Fenske viscometer at $30^{\circ} \mathrm{C}$. Gel permeation chromatography (GPC) was carried out on a Waters chromatography unit interfaced with a Waters 2410 refractive index detector. Two Waters $5 \mu \mathrm{m}$ styragel HR-2 and HR-4 columns (7.8 mm I.D. $\times$ $300 \mathrm{~mm}$ ) connected in series were used with tetrahydrofuran (THF) as the eluent and were calibrated with narrow polystyrene standard. Thermogravimetry analysis (TGA) was conducted with a TA Instrument TGA 2050. Experiments were carried out on 9-11-mg film samples heated in flowing nitrogen or air $\left(90 \mathrm{~cm}^{3} /\right.$ min) at a heating rate of $20^{\circ} \mathrm{C} / \mathrm{min}$. Glass transition temperature $\left(T_{\mathrm{g}}\right)$ were read as the midpoint of the heat capacity jump and were measured on a TA Instruments DSC 2010 at the rate of $15^{\circ} \mathrm{C} / \mathrm{min}$ in flowing nitrogen $\left(40 \mathrm{~cm}^{3} / \mathrm{min}\right)$. Mechanical properties of the films were measured with an Instron model 1130 tensile tester with a $5-\mathrm{kg}$ load cell at a crosshead speed of $5 \mathrm{~cm} / \mathrm{min}$ on strips approximately $40-50 \mu \mathrm{m}$ thick and $0.5 \mathrm{~cm}$ wide with a $2-\mathrm{cm}$ gauge length. An average of at least five individual determinations was used. The color intensity of the polymers was evaluated by a Macbeth Color-eye colorimeter. Measurements were performed with films, using an observational angle of $10^{\circ}$ and a CIE (Commission International de l'Eclairage)-D illuminant. A CIE LAB color difference equation was used. Ultraviolet-visible (UV-vis) spectra of the polymer films were recorded on a Shimadzu UV-1601 UV-vis spectrophotometer. The dielectric property of the polymer films was tested by the parallel-plate capacitor method with a Hewlett Packard 4194A dielectric analyzer. Experiments were performed at $25^{\circ} \mathrm{C}$ in a dry chamber. The equilibrium moisture absorption was determined by the weighing of the changes in vacuum-dried film specimens before and after immersion in deionized water at $25^{\circ} \mathrm{C}$ for $3 \mathrm{~d}$. 


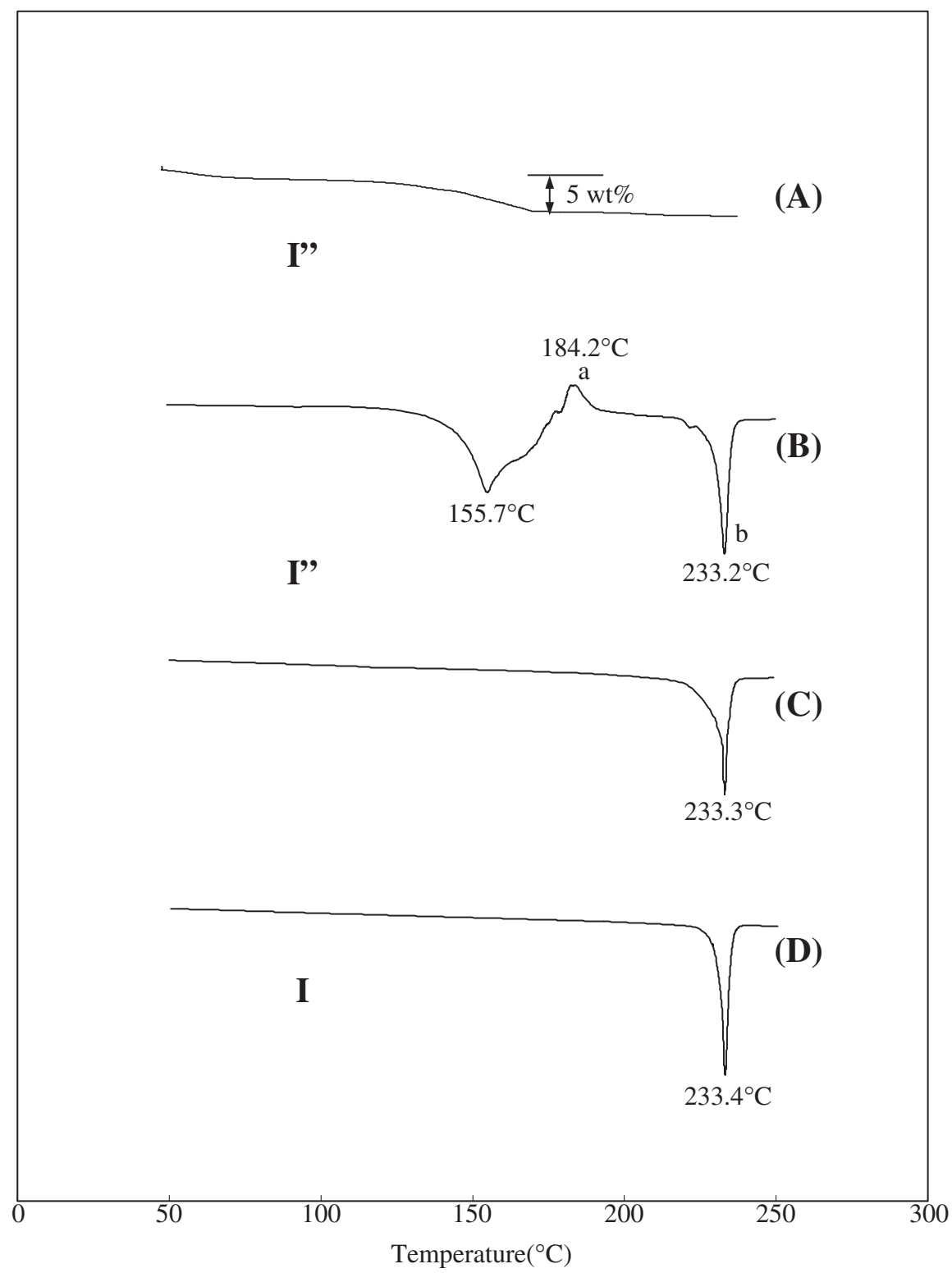

Figure 1. The melt temperature of bis(ether diacid) monomer $\mathbf{I}^{\prime \prime}$ and dianhydride $\mathbf{I}$. The curve (A) was measured by TGA. The curves (B) and (D) were the first DSC scanning curve. The curve (C) was the second DSC scanning curve of $\mathbf{I}^{\prime \prime}$.

\section{RESULTS AND DISCUSSION}

\section{Monomer Synthesis}

Bis(ether anhydride) I containing was prepared by a three-step reaction sequence as shown in Scheme 1 starting from the nitro displacement of 4-nitrophthalonitrile with 6F-bisphenol-A to form bis(ether dinitrile) $\mathbf{I}^{\prime}$. Then, the purified compound of $\mathbf{I}^{\prime}$ was hydrolyzed with $\mathrm{KOH}$ solution of ethanol/water to form the bis(ether diacid) I".

The thermal behavior of $\mathbf{I}^{\prime \prime}$ was investigated with DSC measurement and the result is shown in Figure 1. There are three peaks including of two endothermic peaks and one exothermic peak. The first endothermic peak showed in the range of $110-170^{\circ} \mathrm{C}$ [Figure 1, curve (B)], and its weight loss was about $5 \%$ from the TGA curve [Figure 1(A)]. Therefore, we could presume this temperature range might be the dehydration process of $\mathbf{I}^{\prime \prime}$ by the thermal cyclodehydration to I. On curve (B), the point was exothermic one, indicating the solidification of the dianhydride; the point $\mathrm{b}$ was a melting point of the dianhydride $\mathbf{I}$. The curve (C) was the second DSC scanning curve of $\mathbf{I}^{\prime \prime}$. There is only one endothermic been found and exhibited the melting point of the dianhydride I. It expressed the dianhydride I could be prepared by thermal method. Besides, I" also could be cyclodehydrated by acetic anhydride to obtain the high purity and quantity $\mathbf{I}$, and the melt point of $\mathbf{I}$ was the same with $\mathbf{I}$ which formed by thermal one.

Above-mentioned, the higher purity of the bis(ether 


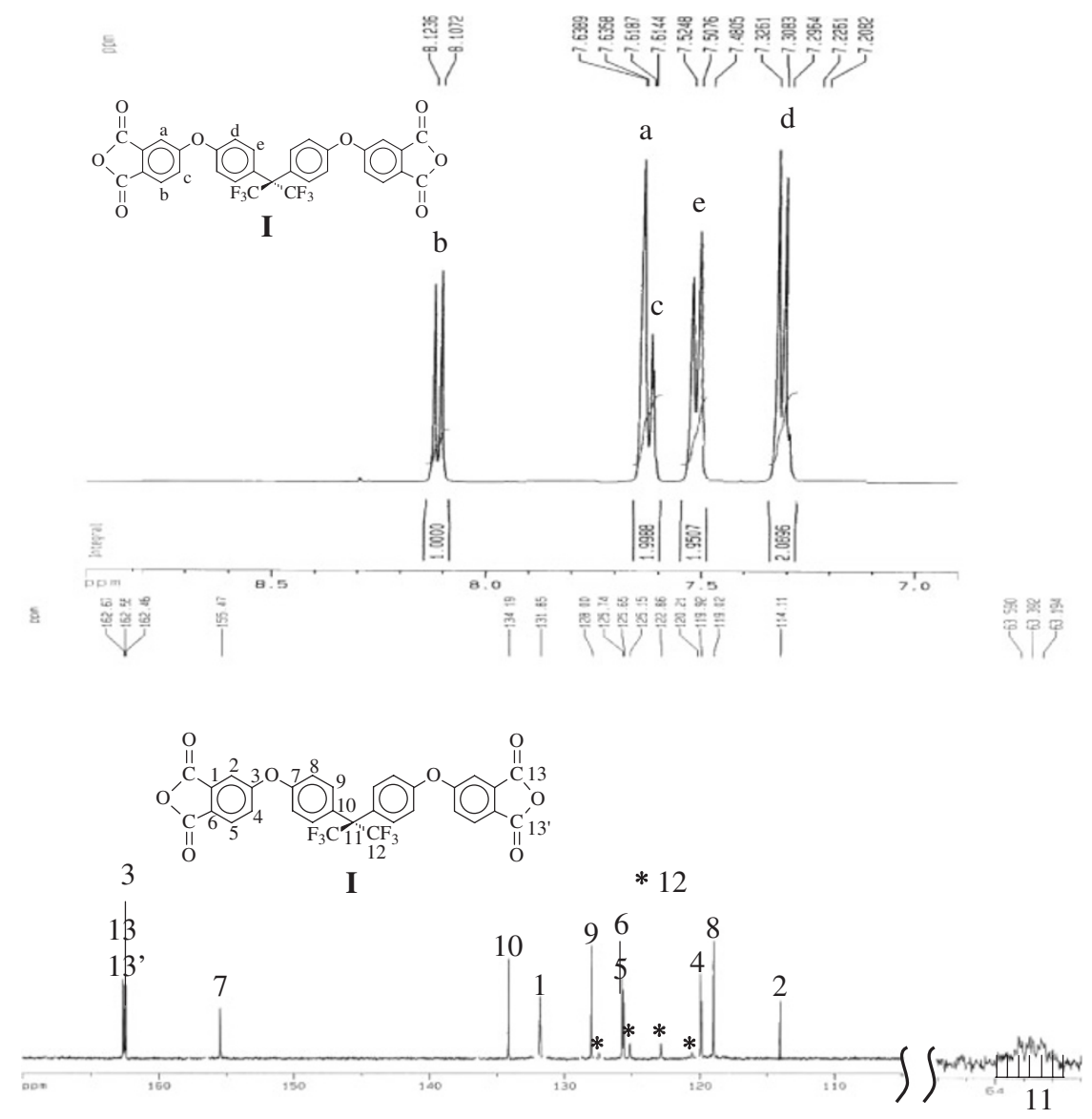

Figure 2. The ${ }^{1} \mathrm{H}$ NMR and ${ }^{13} \mathrm{C}$ spectra of $\mathbf{I}$ in DMSO- $d_{6}$.

anhydride) I could be obtained by thermal or chemical cyclodehydration. However, a polyimide deriving from I which formed by the former method possessed a lower inherent viscosities of $0.51 \mathrm{dL} / \mathrm{g}$ than polyimide derived from $\mathbf{I}$ which formed by the latter method $(0.79 \mathrm{dL} / \mathrm{g})$. This indicated that the reactivity and the degree of polymerization of $\mathbf{I}$ from chemical method with aromatic diamine were better than thermal one. Therefore, these poly(ether imide)s were prepared from the bis(ether anhydride) I which was synthesized by chemical treatment.

In the IR spectrum during the formation of the monomer $\mathbf{I}$, the characteristic peak of cyanide group $\left(2235 \mathrm{~cm}^{-1}\right)$ of $\mathbf{I}^{\prime}$ would be transformed into carbonyl group (3600-2500 $\mathrm{cm}^{-1}$ ) of $\mathbf{I}^{\prime \prime}$, then changed into anhydride group $\left(1851,1770 \mathrm{~cm}^{-1}\right)$. In ${ }^{1} \mathrm{H}$ NMR spectra of $\mathbf{I}^{\prime}, \mathbf{I}^{\prime \prime}$ and $\mathbf{I}$, the aromatic protons of $\mathbf{I}^{\prime}$ resonated in the region of 7.28-8.16 ppm. $\mathrm{H}_{\mathrm{b}}$ closed cyanide group appeared at the farthest downfield, owing to the electron-withdrawing effect of cyanide group. $\mathrm{H}_{\mathrm{a}, \mathrm{c}, \mathrm{d}}$ shifted to higher field due to the electron-donating property of aromatic ether. After $\mathbf{I}^{\prime}$ was hydrolyzed into $\mathbf{I}^{\prime \prime}$, all the aromatic protons of $\mathbf{I}^{\prime \prime}$ shifted to upfield (7.17$7.88 \mathrm{ppm}$ ). The last step, I' was cyclodehydrated to form I, all the protons of I shifted downfield (7.29$8.13 \mathrm{ppm}$ ). Compared with the chemical shift of three compounds, $\mathbf{I}^{\prime}$ had the largest chemical shifts and $\mathbf{I}^{\prime \prime}$ had the smallest one. The reason was probably that the electron-withdrawing effect of cyanide group was larger than others. In ${ }^{13} \mathrm{C}$ NMR spectra, $\mathbf{I}^{\prime}, \mathbf{I}^{\prime \prime}$ and $\mathbf{I}$ all showed 14 main peaks, and the number of carbons was consistent with structures. By comparing the chemical shift of three compounds, it was found that the differences in $\mathrm{C}^{13}$ and $\mathrm{C}^{13^{\prime}}$ were much. $\mathrm{C}^{13,13^{\prime}}$ of cyano group in $\mathbf{I}^{\prime}$ were evidenced in the upfield and $\mathrm{C}^{13,13^{\prime}}$ of carbonyl group in $\mathbf{I}^{\prime \prime}$ and $\mathbf{I}$ were evidenced in the downfield. ${ }^{13} \mathrm{C}$ NMR spectra of these three monomers showed the quartet and septet because of the heteronuclear ${ }^{13} \mathrm{C}-{ }^{19} \mathrm{~F}$ coupling. The quartet occurred in $123 \mathrm{ppm}$ due to the $\mathrm{CF}_{3}$ carbons $\left(\mathrm{C}^{12}\right)$. The one-bond $\mathrm{C}-\mathrm{F}$ coupling constant in this case was about $285 \mathrm{~Hz}$. The $\mathrm{CF}_{3}$-attached carbons $\left(\mathrm{C}^{11}\right)$ showed a septet in about $63 \mathrm{ppm}$ with a smaller coupling constant of about $25 \mathrm{~Hz}$ due to two-bond C-F coupling. All the spectroscopic data obtained were in good agreement with the expected structures.

\section{Polymer Synthesis}

Poly(ether imide)s $\mathbf{I I I}_{\mathbf{a}-\mathbf{g}}$ and $\mathbf{I V}_{\mathbf{a}-\mathbf{g}}$ containing the hexafluoropropane group were synthesized from the bis(ether anhydride) I and various fluorinated or nonfluorinated bis(ether amine)s ( $\mathbf{I I}_{\mathbf{a}-\mathbf{h}}$ or $\mathbf{I I}_{\mathbf{a}-\mathbf{g}}$ ) via a con- 


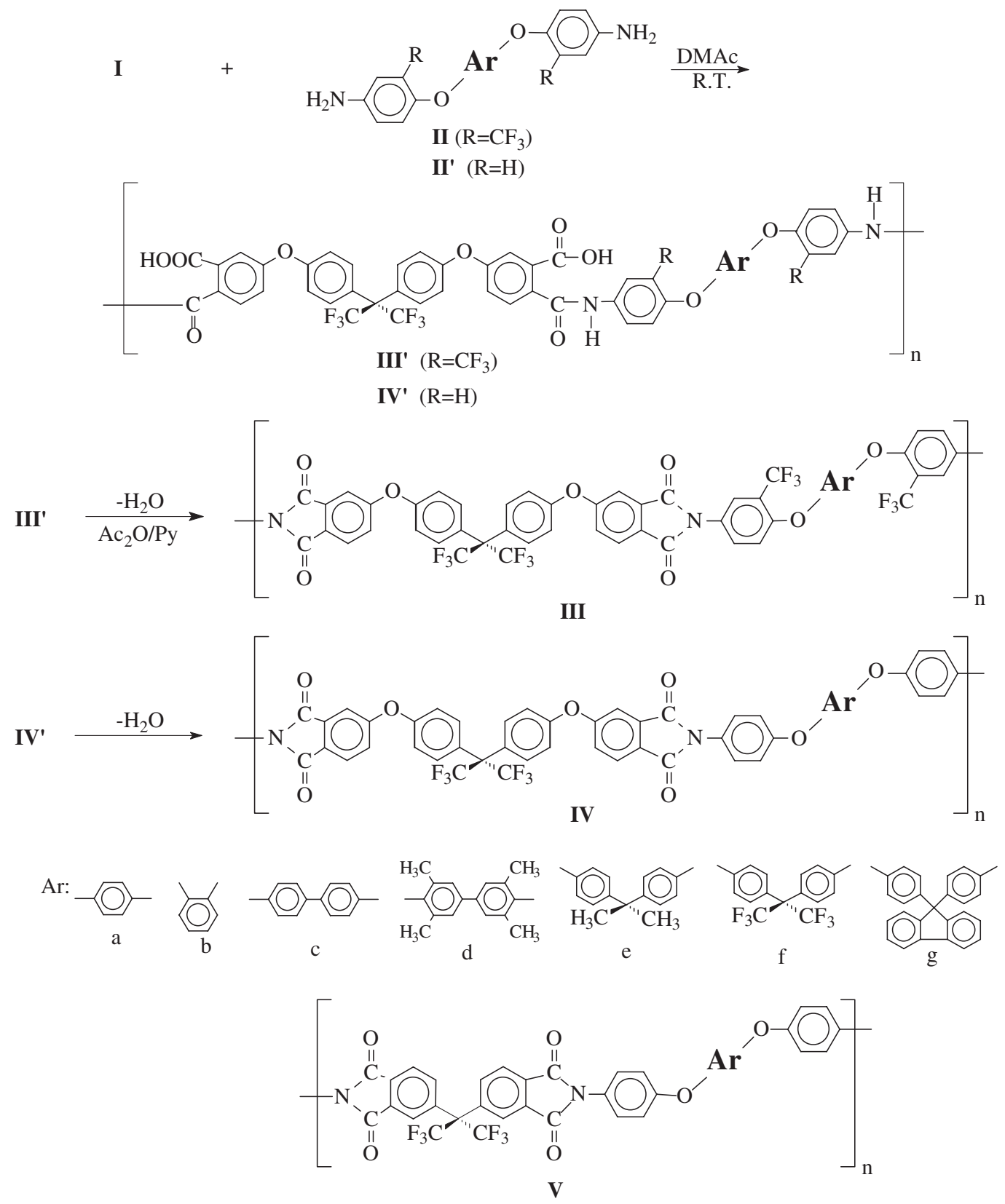

Scheme 2.

ventional two-step procedure of ring-opening polyaddition at room temperature to form PAAs, followed by thermal or chemical imidization (Scheme 2).

These polymers had inherent viscosity in the range of $0.37-0.85 \mathrm{dL} / \mathrm{g}$. The elemental analyses of $\mathbf{I I I}_{\mathbf{a}-\mathbf{g}}$ are listed in Table I, showing that the measured values are close to the calculated ones. The GPC curves of the III series indicated that $M_{\mathrm{w}}$ and $M_{\mathrm{n}}$ values were in the range of $2.85-6.29 \times 10^{4}(\mathrm{~g} / \mathrm{mol})$ and 1.64 $4.02 \times 10^{4}(\mathrm{~g} / \mathrm{mol})$, respectively, relative to the polystyrene standards, and their polydispersity index $\left(M_{\mathrm{w}} / M_{\mathrm{n}}\right)$ values were $1.57-1.83$ (Table II).

A typical IR spectrum of PAA III $_{\mathbf{a}}{ }^{\prime}$ and poly(ether imide) III $_{\mathbf{a}}$ is shown in Figure 3. As the PAA was converted into poly(ether imide), the characteristic absorption bands of the imide ring were observed near $1780,1728 \mathrm{~cm}^{-1}$ (asym. and sym. $\mathrm{C}=\mathrm{O}$ str.), and those of amide and carboxyl group in the regions of $2500-3500 \mathrm{~cm}^{-1}(\mathrm{O}-\mathrm{H}$ and $\mathrm{N}-\mathrm{H}$ str.) and 1716 , $1668 \mathrm{~cm}^{-1}$ ( $\mathrm{C}=\mathrm{O}$ str.) disappeared (Figure 3). Because the chemical imidization method can prevent oxidation during heating process, and obtain polyimide films with lighter color. Thus, these polymers were prepared by chemical imidization and cast into film directly. ${ }^{1} \mathrm{H}$ NMR and ${ }^{13} \mathrm{C}$ NMR spectra of soluble III $_{\mathbf{a}}$ are shown in Figure 4. In ${ }^{1} \mathrm{H}$ NMR spectrum, all the protons of aromatic ring resonated in the region of 7.00-7.95 ppm. $\mathrm{H}_{\mathrm{b}}$ and $\mathrm{H}_{\mathrm{f}}$ closed to the imide ring appeared at the farthest downfield, owing to the inductive effect of electron-withdrawing imide group. Then 
Table I. Inherent viscosity and elemental analysis of the poly(ether imide)s

\begin{tabular}{|c|c|c|c|c|c|c|c|c|}
\hline \multicolumn{4}{|c|}{ Poly(ether imide) $)^{\mathrm{a}}$} & Formula & \multicolumn{4}{|c|}{ Elemental analysis (\%) } \\
\hline Code & $\begin{array}{c}\eta_{\text {inh }} \\
(\mathrm{dL} / \mathrm{g})^{\mathrm{b}}\end{array}$ & Code & $\begin{array}{c}\eta_{\text {inh }} \\
(\mathrm{dL} / \mathrm{g})^{\mathrm{b}}\end{array}$ & $M_{\mathrm{w}}$ & & $\mathrm{C}$ & $\mathrm{H}$ & $\mathrm{N}$ \\
\hline \multirow[t]{2}{*}{$\mathbf{I} \mathbf{V}_{\mathbf{a}}$} & \multirow[t]{2}{*}{0.62} & \multirow[t]{2}{*}{ III $_{\mathbf{a}}$} & \multirow[t]{2}{*}{0.72} & \multirow{2}{*}{$\begin{array}{c}\left(\mathrm{C}_{51} \mathrm{H}_{24} \mathrm{O}_{8} \mathrm{~N}_{2} \mathrm{~F}_{12}\right)_{n} \\
(1020.74)_{n}\end{array}$} & Calcd & 60.01 & 2.37 & 2.74 \\
\hline & & & & & Found & 59.64 & 2.43 & 3.04 \\
\hline \multirow[t]{2}{*}{$\mathbf{I} \mathbf{V}_{\mathbf{b}}$} & \multirow[t]{2}{*}{0.55} & \multirow[t]{2}{*}{ III $_{b}$} & \multirow[t]{2}{*}{0.37} & \multirow{2}{*}{$\begin{array}{c}\left(\mathrm{C}_{51} \mathrm{H}_{24} \mathrm{O}_{8} \mathrm{~N}_{2} \mathrm{~F}_{12}\right)_{n} \\
(1020.74)_{n}\end{array}$} & Calcd & 60.01 & 2.37 & 2.74 \\
\hline & & & & & Found & 60.05 & 2.92 & 3.07 \\
\hline \multirow[t]{2}{*}{$\mathbf{I} \mathbf{V}_{\mathbf{c}}$} & \multirow[t]{2}{*}{0.85} & \multirow[t]{2}{*}{ IIII $_{c}$} & \multirow[t]{2}{*}{0.62} & \multirow{2}{*}{$\begin{array}{c}\left(\mathrm{C}_{57} \mathrm{H}_{28} \mathrm{O}_{8} \mathrm{~N}_{2} \mathrm{~F}_{12}\right)_{n} \\
(1096.84)_{n}\end{array}$} & Calcd & 62.42 & 2.57 & 2.55 \\
\hline & & & & & Found & 62.42 & 2.99 & 2.83 \\
\hline \multirow[t]{2}{*}{$\mathbf{I} \mathbf{V}_{\mathrm{d}}$} & \multirow[t]{2}{*}{0.76} & \multirow[t]{2}{*}{ III $_{d}$} & \multirow[t]{2}{*}{0.75} & \multirow{2}{*}{$\begin{array}{c}\left(\mathrm{C}_{61} \mathrm{H}_{36} \mathrm{O}_{8} \mathrm{~N}_{2} \mathrm{~F}_{12}\right)_{n} \\
(1152.95)_{n}\end{array}$} & Calcd & 63.55 & 3.15 & 2.43 \\
\hline & & & & & Found & 63.22 & 3.40 & 2.34 \\
\hline \multirow[t]{2}{*}{$\mathbf{I} \mathbf{V}_{\mathrm{e}}$} & \multirow[t]{2}{*}{0.55} & \multirow[t]{2}{*}{ IIII $_{e}$} & \multirow[t]{2}{*}{0.43} & \multirow{2}{*}{$\begin{array}{c}\left(\mathrm{C}_{60} \mathrm{H}_{34} \mathrm{O}_{8} \mathrm{~N}_{2} \mathrm{~F}_{12}\right)_{n} \\
(1138.92)_{n}\end{array}$} & Calcd & 63.28 & 3.01 & 2.46 \\
\hline & & & & & Found & 62.83 & 3.15 & 2.72 \\
\hline \multirow[t]{2}{*}{$\mathbf{I} \mathbf{V}_{\mathbf{f}}$} & \multirow[t]{2}{*}{0.57} & \multirow[t]{2}{*}{ III $_{\mathbf{f}}$} & \multirow[t]{2}{*}{0.43} & \multirow{2}{*}{$\begin{array}{c}\left(\mathrm{C}_{60} \mathrm{H}_{28} \mathrm{O}_{8} \mathrm{~N}_{2} \mathrm{~F}_{18}\right)_{n} \\
(1246.86)_{n}\end{array}$} & Calcd & 57.80 & 2.26 & 2.25 \\
\hline & & & & & Found & 57.79 & 2.67 & 2.34 \\
\hline \multirow[t]{2}{*}{$\mathbf{I V}_{\mathrm{g}}$} & \multirow[t]{2}{*}{0.49} & \multirow[t]{2}{*}{ III $_{\mathrm{g}}$} & \multirow[t]{2}{*}{0.51} & $\left(\mathrm{C}_{69} \mathrm{H}_{36} \mathrm{O}_{8} \mathrm{~N}_{2} \mathrm{~F}_{12}\right)_{n}$ & Calcd & 66.35 & 2.91 & 2.24 \\
\hline & & & & $(1249.03)_{n}$ & Found & 66.04 & 2.94 & 2.59 \\
\hline
\end{tabular}

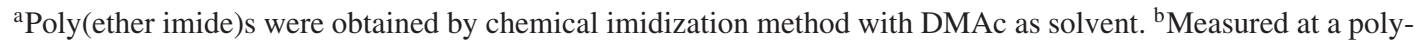
mer concentration of $0.5 \mathrm{~g} / \mathrm{dL}$ in DMAc at $30^{\circ} \mathrm{C}$.

Table II. GPC data of poly(ether imide)s III

\begin{tabular}{cccc}
\hline Polymer $^{\mathrm{b}}$ & $\begin{array}{c}M_{\mathrm{n}}\left(\times 10^{4}\right) \\
(\mathrm{g} / \mathrm{mol})\end{array}$ & $\begin{array}{c}M_{\mathrm{w}}\left(\times 10^{4}\right) \\
(\mathrm{g} / \mathrm{mol})\end{array}$ & $M_{\mathrm{w}} / M_{\mathrm{n}}$ \\
\hline $\mathbf{I I I}_{\mathbf{a}}$ & 3.45 & 5.74 & 1.59 \\
$\mathbf{I I I}_{\mathbf{b}}$ & 2.35 & 4.31 & 1.83 \\
$\mathbf{I I I}_{\mathbf{c}}$ & 2.95 & 4.87 & 1.65 \\
$\mathbf{I I I}_{\mathbf{d}}$ & 4.02 & 6.29 & 1.57 \\
$\mathbf{I I I}_{\mathbf{e}}$ & 1.64 & 2.85 & 1.74 \\
$\mathbf{I I I}_{\mathbf{f}}$ & 1.95 & 3.12 & 1.60 \\
$\mathbf{I I I}_{\mathbf{g}}$ & 2.60 & 4.67 & 1.64 \\
\hline
\end{tabular}

${ }^{\text {a }}$ Relative to polystyrene standard, using THF as the eluent. ${ }^{b}$ Poly(ether imide)s were obtained by chemical imidization method with DMAc as solvent.

$\mathrm{H}_{\mathrm{c}, \mathrm{d}, \mathrm{i}}$ and $\mathrm{H}_{\mathrm{h}}$ shifted to the higher field due to the electron-donating property of aromatic ether. $\mathrm{In}^{13} \mathrm{C}$ NMR spectra, because $\mathrm{C}^{22}$ and $\mathrm{C}^{8}$ overlaps of $\mathrm{C}^{23}$ and $\mathrm{C}^{17}$, respectively, it showed 21 signals and the peaks of the spectra were less than calculation. Carbons $\mathrm{C}^{22}$ and $\mathrm{C}^{23}$ of the carbonyl group were evidenced in the downfield. Moreover, there were three quartets and one septet because of the heteronuclear ${ }^{13} \mathrm{C}-{ }^{19} \mathrm{~F}$ coupling. The large quartet centered at about 123 and $124 \mathrm{ppm}$ was due to the $\mathrm{CF}_{3}$ carbon $\left(\mathrm{C}^{12}, \mathrm{C}^{19}\right)$. The one-bond $\mathrm{C}-\mathrm{F}$ coupling constant in this case was about 285 and $271 \mathrm{~Hz}$. Another quartet centered at about $119 \mathrm{ppm}$ was the $\mathrm{CF}_{3}$-attached carbon $\left(\mathrm{C}^{15}\right)$ with a smaller coupling constant of about $31 \mathrm{~Hz}$ due to two-bond $\mathrm{C}-\mathrm{F}$ coupling. The $\mathrm{CF}_{3}$-attached carbons $\left(\mathrm{C}^{11}\right)$ showed a septet centered at about $63.5 \mathrm{ppm}$ had a coupling constant $(\mathrm{ca} .25 \mathrm{~Hz})$ because two-bond $\mathrm{C}-\mathrm{F}$ coupling. Above-cited results evidence that the III series been synthesized successfully.

\section{Properties of Polymers}

Solubility of the poly(ether imide)s III and IV series was studied quantitatively, and the results are listed in Table III. Because of the monomers dianhydride and diamine both contained $\mathrm{CF}_{3}$ group and ether chains, all III series exhibited excellent solubility above $10 \mathrm{wt} / \mathrm{v} \%$ concentration in the amide-type solvents including NMP, DMAc and DMF, and in dichloromethane, chloroform, THF, pyridine, and $m$ cresol. Most of the III series also showed good solubility in DMSO at a concentration of $10 \mathrm{wt} / \mathrm{v} \%$ except for $\mathbf{I I I}_{\mathbf{d}}$ with $3,3^{\prime}, 5,5^{\prime}$-tetramethylbiphenyl group being insoluble. The IV series could be dissolved in THF and chloroform at $10 \mathrm{wt} / \mathrm{v} \%$ concentration, but the solubility of the IV series in other solvents was lower in comparison with the III series. For example, most of the III series were soluble in the amide-type solvents above $10 \mathrm{wt} / \mathrm{v} \%$, but the IV series only could dissolve above $5 \mathrm{wt} / \mathrm{v} \%$. The solubility of the III and IV series was much different in DMSO and acetone. Most of the III series could be dissolved in DMSO and acetone except $\mathbf{I I I}_{\mathbf{d}}$, but most of the IV series could not. $\mathbf{I V}_{\mathbf{b}}$ showed better solubility in DMSO, $m$-cresol and $\mathrm{CH}_{2} \mathrm{Cl}_{2}$ because the $\mathrm{Ar}$ was ortho substitute as compared with $\mathbf{I V}_{\mathbf{a}}$.

The color intensities of the polymer films were elucidated from the yellowness $\left(\mathrm{b}^{*}\right)$, redness $\left(\mathrm{a}^{*}\right)$ or lightness $\left(\mathrm{L}^{*}\right)$ indices observed by a colorimeter. In this case, we based our judgment of the degree of yellowness on the $b^{*}$ value. The color coordinates of the III and IV series are given in Table IV.

The $b^{*}$ value of the III(C) series prepared via chemical imidization was in the range of $6.2-7.0$ and the lightness $\left(\mathrm{L}^{*}\right)$ value was above $98.5 \%$, and 


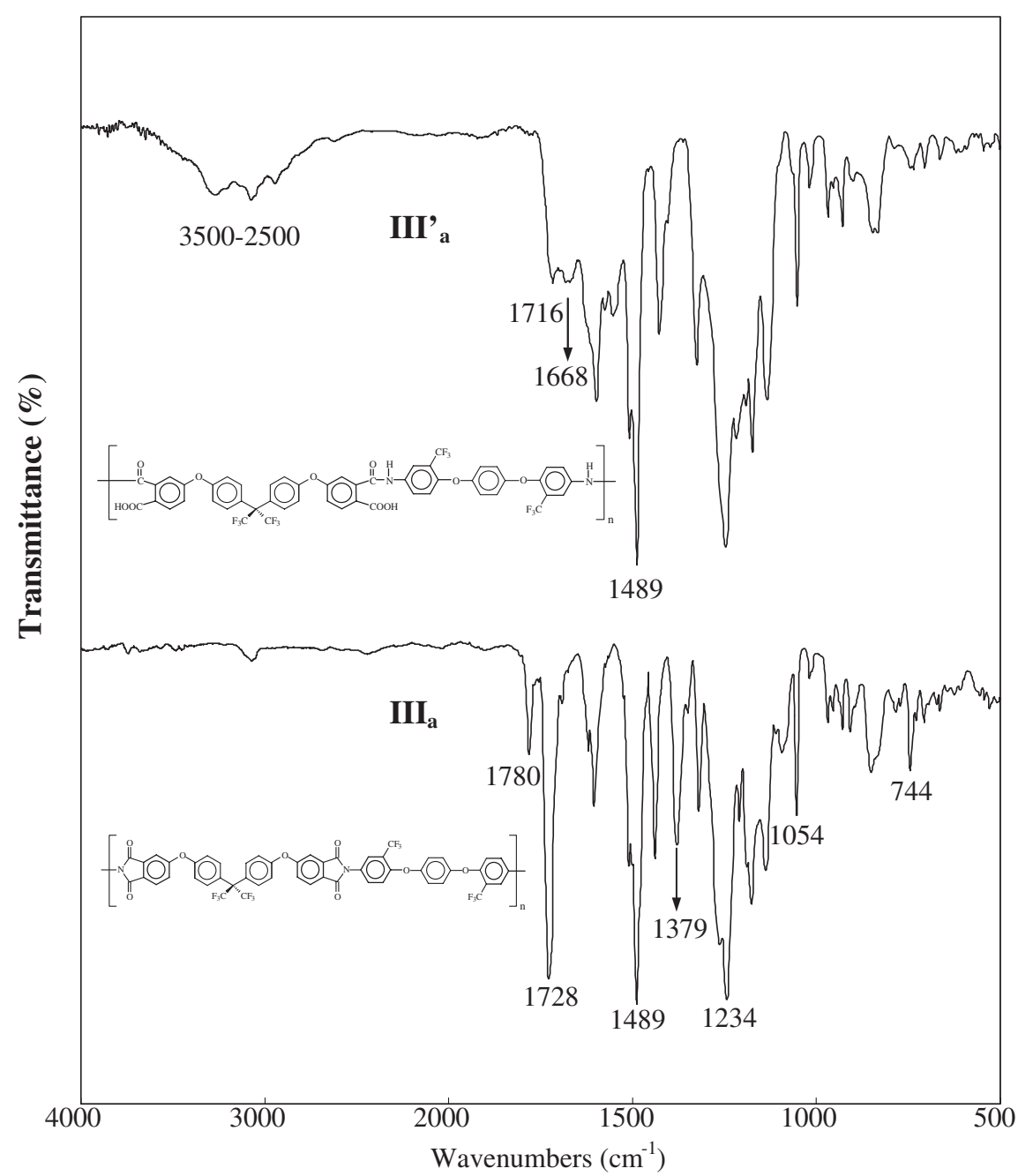

Figure 3. FT-IR spectra of representative poly(amic acid) $\mathbf{I I I}_{\mathbf{a}}$ and poly(ether imide) $\mathbf{I I I}_{\mathbf{a}}$.

showed high lightness. The difference in $b^{*}$ value between the III series was unobvious, indicated that the influence on color by the structure of diamines was slight. On comparing with the $\mathbf{I I I}(\mathbf{H})$ series prepared by thermal imidization, the III(C) series showed lighter color $\left(\Delta b^{*}\right.$ is in the range of 3.2-5.1). Compared III(C) series with $\mathbf{I V}(\mathbf{C})$ series, the nonfluorinated IV $(\mathbf{C})$ series had the $\mathrm{b}^{*}$ value of $12.0-13.1$ except $\mathbf{I V}_{\mathbf{f}}$, and were higher than $\mathbf{I I I}(\mathbf{C})$ about 5-6. The $b^{*}$ value of $\mathbf{I V}_{\mathbf{f}}(\mathbf{C})$ was close to the $\mathbf{I I I}(\mathbf{C})$. It was attributed to the Ar structure with hexafluoroisopropylidene group. The $b^{*}$ value of the $\mathbf{I V}(\mathbf{H})$ showed higher than $\mathbf{I V}(\mathbf{C})$ about 3.0. Though the increasing of the $\Delta b^{*}$ value in the IV series was smaller than it in the III series, the $b^{*}$ value of the $\mathbf{I V}(\mathbf{H})$ series was higher than III (H) series about 5.0. The polyimide $\mathbf{V}(\mathbf{C})$ series, based on 6FDA, is general considered as the most transparent and color-lighted polyimide. Compare the color of the $\mathbf{I V}(\mathbf{C})$ series with the $\mathbf{V}(\mathbf{C})$ series, the $b^{*}$ values of the $\mathbf{V}$ series ranging 21.4-28.7 except $\mathbf{V}_{\mathbf{f}}$ and were higher than $\mathbf{I V}(\mathbf{C})$ series $\left(\Delta \mathrm{b}^{*}=8.9-14.8\right)$. Therefore, the polyimides de- rived from bis(ether anhydride) containing hexafluoroisopropylidene group were lighter than polyimide based on 6FDA ( $\mathbf{V}$ series). The color of polyimide is also related to the structure of dianhydride components. For example, $\mathbf{I V}_{\mathbf{a}}$ derived from $\mathbf{I I}_{\mathbf{a}}^{\prime}$ showed lower $b^{*}$ value than six corresponding polyimides as shown in Table IV. The polyimide films of PMDA/ $\mathbf{I I}_{\mathbf{a}}{ }^{\prime}$ and $\mathrm{BTDA} / \mathbf{I I}_{\mathbf{a}}{ }^{\mathbf{a}}$ appeared a deeper yellow and showed relatively high $\mathrm{b}^{*}$ values above 80 . BPDA/ $\mathbf{I I}_{\mathbf{a}}{ }^{\prime}$ and DSDA $/ \mathbf{I I}_{\mathbf{a}}{ }^{\prime}$ revealed a slightly reduced $\mathrm{b}^{*}$ values of 65.9 and 60.1 , respectively. $6 \mathrm{FDA} / \mathbf{I I}_{\mathbf{a}}{ }_{\mathbf{a}}$ (the $\mathbf{V}_{\mathbf{a}}(\mathbf{H})$ ) and ODPA/ $/ \mathbf{I I}^{\prime}{ }_{\mathbf{a}}$ were pale yellow in color and showed the $b^{*}$ values of 34.7 and 30.4 , respectively. In contrast with the $\mathrm{b}^{*}$ value of common polyimides, the $\mathbf{I V}_{\mathbf{a}}$ had a low value (16.1). Moreover, $\mathbf{I I I}_{\mathbf{a}}(\mathbf{H})$ derived from $\mathbf{I}$ with $\mathbf{I I}_{\mathbf{a}}$ had the lower $\mathbf{b}^{*}$ value of 11.5. If $\mathbf{I I I}_{\mathbf{a}}$ was prepared via chemical imidization, III $_{\mathbf{a}}(\mathbf{C})$ could obtain the lowest $\mathrm{b}^{*}$ value and was close to colorless.

Moreover, the color intensity of the III series could also be elucidated from the cutoff $\left(\lambda_{0}\right)$ observed in UV-vis absorption spectra. The $\lambda_{0}$ values of the III 


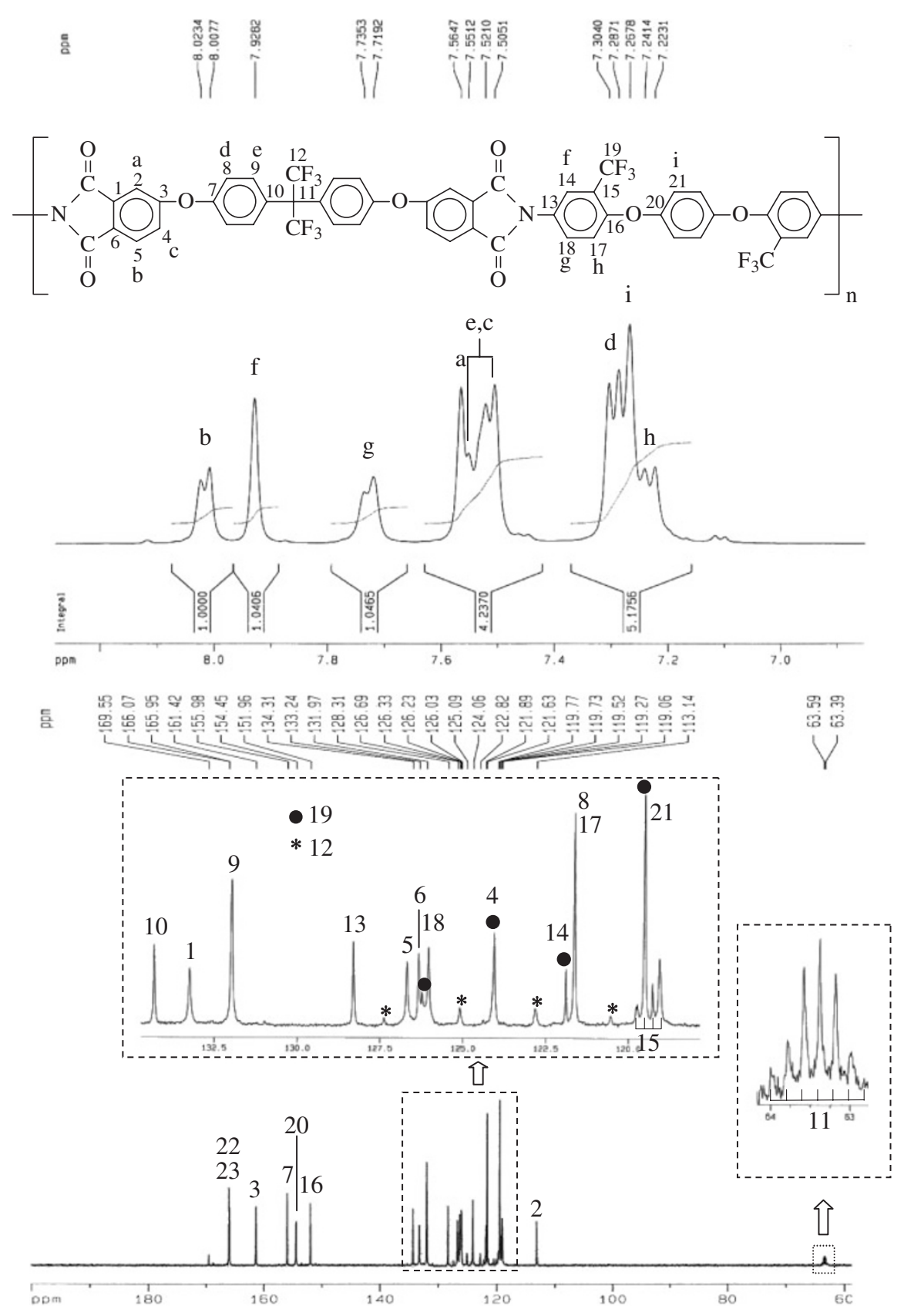

Figure 4. The ${ }^{1} \mathrm{H}$ and ${ }^{13} \mathrm{C}$ NMR spectra of poly(ether imide) $\mathbf{I I I}_{\mathbf{a}}$ in DMSO- $d_{6}$.

and IV series were recorded in the range of 364367 and $368-371 \mathrm{~nm}$, respectively, and they exhibited high transparence and colorless in visible region (Table IV). The $\lambda_{0}$ values of the III series were shorter than the IV series and the difference in $\lambda_{0}$ value between these two series is $2-4 \mathrm{~nm}$. Compared the IV with $\mathbf{V}$ series and common polyimides, the IV series showed the lower $\lambda_{0}$ value. Consistent with the results obtained from the colorimeter. To summarize, both the III and IV series were lightly-colored, the III series especially. The results of colorless polyimide films (the III and IV series) were attributed to the structures of bis(ether anhydride). The high purity and colorless bis(ether anhydride) containing hexafluoroisopropyli- dene and ether chains can be prepared and is effective in preventing the CTC formation. Then, the III series is lighter-colored than the IV series because of the bis(ether amine) with the pendent $\mathrm{CF}_{3}$ group also can reduces CTC formation to form colorless polyimide films.

The results of tensile test are summarized in Table V. The films III and IV series had tensile strength of 77-102 MPa, initial modulus of 1.5-2.1 $\mathrm{GPa}$, and elongation at break above $8 \%$ except $\mathbf{I I I}_{\mathbf{b}}$. $\mathbf{I V}_{\mathbf{e}}$ and $\mathbf{I V}_{\mathbf{f}}$ showed distinct yield point on stressstrain curves (the yield strength of 96 and $100 \mathrm{MPa}$ ) and moderate elongation at break. The incorporation of the $\mathrm{CF}_{3}$ group into the structure of poly(ether 
Organo-soluble and Lightly-colored Fluorinated Polyimides

Table III. Solubility ${ }^{\mathrm{a}}$ of poly(ether imide)s

\begin{tabular}{|c|c|c|c|c|c|c|c|c|}
\hline \multirow[b]{2}{*}{ Polymer $^{\mathrm{c}}$} & \multicolumn{8}{|c|}{ Solvents ${ }^{b}$} \\
\hline & $\begin{array}{l}\text { NMP } \\
\text { DMAc } \\
\text { DMF }\end{array}$ & DMSO & $m$-Cresol & Py & THF & $\mathrm{CH}_{2} \mathrm{Cl}_{2}$ & $\mathrm{CHCl}_{3}$ & Acetone \\
\hline III $_{a}$ & +++ & +++ & ++ & +++ & +++ & +++ & +++ & $\mathrm{S}$ \\
\hline IIII $_{b}$ & +++ & +++ & +++ & +++ & +++ & +++ & +++ & +++ \\
\hline IIII $_{c}$ & +++ & ++ & ++ & +++ & +++ & +++ & +++ & S \\
\hline III $_{d}$ & +++ & - & ++ & +++ & +++ & +++ & +++ & $\mathrm{S}$ \\
\hline IIII $_{e}$ & +++ & +++ & +++ & +++ & +++ & +++ & +++ & +++ \\
\hline IIII $_{\mathbf{f}}$ & +++ & +++ & +++ & +++ & +++ & +++ & +++ & +++ \\
\hline $\mathrm{III}_{\mathrm{g}}$ & +++ & +++ & +++ & +++ & +++ & +++ & +++ & +++ \\
\hline $\mathbf{I V}_{\mathrm{a}}$ & ++ & - & - & ++ & +++ & $\mathrm{S}$ & +++ & - \\
\hline $\mathbf{I V}_{\mathrm{b}}$ & +++ & + & + & +++ & +++ & +++ & +++ & - \\
\hline $\mathbf{I V}_{\mathrm{c}}$ & ++ & - & - & + & +++ & S & +++ & - \\
\hline $\mathbf{I V}_{\mathrm{d}}$ & ++ & - & - & ++ & +++ & +++ & +++ & - \\
\hline $\mathbf{I V}_{\mathrm{e}}$ & ++ & - & - & ++ & +++ & +++ & +++ & - \\
\hline $\mathbf{I V}_{\mathbf{f}}$ & ++ & - & + & +++ & +++ & +++ & +++ & - \\
\hline $\mathbf{I V}_{\mathrm{g}}$ & ++ & - & - & +++ & +++ & +++ & +++ & - \\
\hline
\end{tabular}

${ }^{a}$ Quantitative solubility: $(+++) 100 \mathrm{mg}$ dissolved in $1 \mathrm{~mL}(10 \%),(++) 5 \%,(+) 1 \%$, (S) swelling, (-)

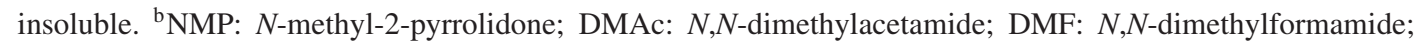
DMSO: dimethylsulfoxide; Py: pyridine; THF: tetrahydrofuran. ${ }^{\mathrm{c} P o l y}$ (ether imide)s were obtained by chemical imidization method with DMAc as solvent.

imide)s would not reduce mechanical properties obviously. These results indicate that all these polymer films possess good tensile properties with strong and tough character.

The thermal behavior data of all the poly(ether imide)s are summarized in Table VI. DSC experiment were rapid cooling from $400^{\circ} \mathrm{C}$ to room temperature produced predominantly amorphous samples, so the $T_{\mathrm{g}}$ of all the polymers could be easily read in the second heating DSC traces. The $T_{\mathrm{g}}$ values of the III and IV series were in the range of $196-265^{\circ} \mathrm{C}$, correlating with that of chain flexibility and depending on the structure of the diamine moieties. When the Ar of the phenylene structures of $\mathbf{I I I}_{\mathbf{a}}\left(\mathbf{I V}_{\mathbf{a}}\right)$ and $\mathbf{I I I}_{\mathbf{b}}\left(\mathbf{I V}_{\mathbf{b}}\right)$ were compared, the $\mathbf{I I I}_{\mathbf{b}}\left(\mathbf{I V}_{\mathbf{b}}\right)$ showed lower $T_{\mathrm{g}}$ value, owing to the asymmetrical $o$-phenylene unit of polymer chain and made rotation difficulty. Those derived from biphenyl in diamine moieties such as $\mathbf{I I I}_{\mathbf{c}, \mathbf{d}}$, $\mathbf{I V}_{\mathbf{c}, \mathbf{d}}$, the $\mathbf{I I I}_{\mathbf{d}}$ and $\mathbf{I V}_{\mathbf{d}}$ showed the highest $T_{\mathrm{g}}$ value due to the structure of 3,3',5,5'-tetramethylbiphenyl group which hinder the segmental mobility and hence leads to a high $T_{\mathrm{g}}$ value. As the "Ar" containing tetraphenylen-diether of $\mathbf{I I I}_{\mathbf{e}}\left(\mathbf{I V}_{\mathbf{e}}\right), \mathbf{I I I}_{\mathbf{f}}\left(\mathbf{I V}_{\mathbf{f}}\right)$ and $\mathbf{I I I}_{\mathbf{g}}\left(\mathbf{I V}_{\mathbf{g}}\right)$, $\mathbf{I I I}_{\mathbf{g}}\left(\mathbf{I V}_{\mathbf{g}}\right)$, they uneasily rotate by the asymmetrical bulky group, so the $T_{\mathrm{g}}$ of $\mathbf{I I I}_{\mathbf{g}}\left(\mathbf{I V}_{\mathbf{g}}\right)$ are higher than $\mathbf{I I I}_{\mathbf{e}}\left(\mathbf{I V}_{\mathbf{e}}\right)$ and $\mathbf{I I I}_{\mathbf{f}}\left(\mathbf{I V}_{\mathbf{f}}\right)$. The $T_{\mathrm{g}}$ values of $\mathbf{I I I}_{\mathbf{f}}$ and $\mathbf{I V}_{\mathbf{f}}$ were higher than $\mathbf{I I I}_{\mathbf{e}}$ and $\mathbf{I V}_{\mathbf{e}}$ respectively, due to the of $\mathrm{C}-\mathrm{F}$ bond of $\mathrm{CF}_{3}$ group is stronger than $\mathrm{C}-\mathrm{H}$ bond of $\mathrm{CH}_{3}$ group. Comparison the $T_{\mathrm{g}}$ values between the III and IV series, all III $_{\mathbf{a}-\mathbf{g}}$ bearing pendent
$\mathrm{CF}_{3}$ group so that the packing density of polymer was decreased and free volume between polymers was increased, which generally resulted in reduced $T_{\mathrm{g}}$.

The decomposition temperatures of all poly(ether imide)s at $10 \%$ weight loss $\left(T_{10}\right)$ in nitrogen and air atmospheres were determined from original TGA curves. The $T_{10}$ values of $\mathbf{I I I}_{\mathbf{a}-\mathbf{g}}$ in nitrogen and air stayed within $495-567^{\circ} \mathrm{C}$ and within $492-558^{\circ} \mathrm{C}$, respectively. All $T_{10}$ values of $\mathbf{I V}_{\mathrm{a}-\mathrm{g}}$ were above $500^{\circ} \mathrm{C}$ in nitrogen and air. $\mathbf{I I I}_{\mathbf{g}}$ and $\mathbf{I V}_{\mathbf{g}}$ showed the highest $T_{10}$ value in nitrogen or in air due to the Ar containing more aromatic rings. $\mathbf{I I I}_{\mathbf{d}}$ and $\mathbf{I V}_{\mathbf{d}}$ showed the lowest $T_{10}$ value in nitrogen or in air, because the methyl group linkages to the side chain of phenyl is decomposed easily in the heating process. The $T_{10}$ values of all polymers in nitrogen were higher than in air except $\mathbf{I I I} \mathbf{I}_{\mathbf{b}}, \mathbf{I} \mathbf{V}_{\mathbf{d}}$ and $\mathbf{I} \mathbf{V}_{\mathbf{e}}$. The phenomenon of $\mathbf{I} \mathbf{V}_{\mathbf{d}}$ was especially obvious, and its TGA curves were shown in Figure $5 . \mathbf{I V}_{\mathbf{d}}$ showed higher char yield in air than in $\mathrm{N}_{2}$ within $490-570^{\circ} \mathrm{C}$, possibly due to the methyl groups were easily oxidized to form a free radical, causing cross-linking between intermolecular and delaying the decomposition rate of the polymer. The III and IV series had the char yield in the range of 49-57 and 53-62 wt \% at $800{ }^{\circ} \mathrm{C}$ in nitrogen, respectively. Both $\mathbf{I I I}_{\mathbf{g}}$ and $\mathbf{I V}_{\mathbf{g}}$ containing fluorene group exhibited better thermal stability than others'.

The results of dielectric properties and moisture absorptions of the III and IV series are shown in Table VII. The dielectric constants of the III series 
Table IV. Color coordinates and cut-off wavelength $\left(\lambda_{0}\right)$ from UV-vis spectra for III and IV series poly(ether imide) films

\begin{tabular}{|c|c|c|c|c|c|c|}
\hline \multirow{2}{*}{ Polymer ${ }^{b, c}$} & \multicolumn{3}{|c|}{ Color Coordinates $^{\mathrm{a}}$} & \multirow{2}{*}{$\Delta \mathrm{b}^{*}$} & \multirow{2}{*}{$\lambda_{0}(\mathrm{~nm})$} & \multirow{2}{*}{$\begin{array}{c}\text { Film } \\
\text { thickness }(\mu \mathrm{m})\end{array}$} \\
\hline & $\mathrm{b}^{*}$ & $\mathrm{a}^{*}$ & $\mathrm{~L}^{*}$ & & & \\
\hline Ref. Std & 0.09 & -0.02 & 100.0 & & & \\
\hline $\mathrm{III}_{\mathrm{a}}(\mathrm{C})$ & 7.0 & -1.0 & 98.5 & & 367 & 53 \\
\hline $\operatorname{III}_{\mathbf{b}}(\mathrm{C})$ & 6.7 & -1.4 & 98.9 & & 367 & 59 \\
\hline $\mathrm{III}_{\mathrm{c}}(\mathrm{C})$ & 6.6 & -1.1 & 98.9 & & 366 & 48 \\
\hline $\operatorname{III}_{d}(C)$ & 6.9 & -1.8 & 99.3 & & 366 & 46 \\
\hline $\operatorname{III}_{e}(C)$ & 6.7 & -1.4 & 99.6 & & 367 & 41 \\
\hline $\operatorname{III}_{\mathbf{f}}(\mathbf{C})$ & 6.2 & -1.1 & 98.7 & & 362 & 65 \\
\hline $\operatorname{III}_{\mathrm{g}}(\mathrm{C})$ & 6.4 & -1.4 & 98.9 & & 365 & 62 \\
\hline $\operatorname{III}_{\mathrm{a}}(\mathrm{H})$ & 11.5 & -1.6 & 97.0 & 4.5 & 371 & 62 \\
\hline $\operatorname{III}_{\mathrm{c}}(\mathbf{H})$ & 9.8 & -1.9 & 98.3 & 3.2 & 368 & 69 \\
\hline $\mathrm{III}_{\mathrm{d}}(\mathrm{H})$ & 12.0 & -2.8 & 98.3 & 5.1 & 369 & 60 \\
\hline $\mathbf{I V}_{\mathrm{a}}(\mathbf{C})$ & 13.1 & -3.3 & 97.7 & 6.1 & 371 & 55 \\
\hline $\mathbf{I V}_{\mathrm{b}}(\mathrm{C})$ & 12.1 & -3.4 & 98.4 & 5.4 & 369 & 46 \\
\hline $\mathbf{I V}_{\mathrm{c}}(\mathrm{C})$ & 12.0 & -3.3 & 97.9 & 5.4 & 369 & 54 \\
\hline $\mathbf{I V}_{\mathrm{d}}(\mathrm{C})$ & 12.8 & -4.3 & 97.8 & 5.9 & 370 & 52 \\
\hline $\mathrm{IV}_{\mathrm{e}}(\mathrm{C})$ & 12.7 & -3.1 & 98.0 & 6.0 & 370 & 43 \\
\hline $\mathbf{I V}_{\mathbf{f}}(\mathbf{C})$ & 8.3 & -1.8 & 98.3 & 2.1 & 368 & 43 \\
\hline $\mathbf{I V}_{\mathbf{g}}(\mathbf{C})$ & 12.3 & -3.3 & 97.8 & 5.9 & 370 & 58 \\
\hline $\mathrm{IV}_{\mathrm{a}}(\mathrm{H})$ & 16.1 & -3.3 & 97.0 & 2.2 & 374 & 30 \\
\hline $\mathbf{V I}_{\mathbf{c}}(\mathbf{H})$ & 15.0 & -3.4 & 97.6 & 3.0 & 373 & 32 \\
\hline $\mathbf{V}_{\mathrm{a}}(\mathbf{C})$ & 28.7 & -10.2 & 98.3 & 14.8 & 393 & 76 \\
\hline $\mathbf{V}_{\mathbf{b}}(\mathbf{C})$ & 22.9 & -8.8 & 99.1 & 10.8 & 383 & 47 \\
\hline $\mathbf{V}_{\mathbf{c}}(\mathbf{C})$ & 25.4 & -9.5 & 98.6 & 13.4 & 389 & 52 \\
\hline$V_{d}(C)$ & 27.9 & -10.6 & 99.2 & 11.1 & 388 & 42 \\
\hline $\mathbf{V}_{\mathrm{e}}(\mathbf{C})$ & 22.1 & -8.4 & 99.0 & 9.4 & 382 & 53 \\
\hline $\mathbf{V}_{\mathrm{f}}(\mathbf{C})$ & 12.6 & -5.0 & 99.3 & 4.3 & 370 & 48 \\
\hline $\mathbf{V}_{\mathrm{g}}(\mathrm{C})$ & 21.4 & -7.7 & 98.6 & 4.8 & 379 & 54 \\
\hline $\mathbf{V}_{\mathrm{a}}(\mathbf{H})$ & 34.7 & -5.2 & 92.2 & 11.6 & 388 & 47 \\
\hline $\operatorname{PMDA}_{-I^{\prime}}{ }_{\mathbf{a}}(\mathbf{H})$ & 80.5 & 3.7 & 88.1 & & 440 & 39 \\
\hline BTDA-II' ${ }_{\mathrm{a}}^{\prime}(\mathbf{H})$ & 87.8 & 2.3 & 90.0 & & 446 & 37 \\
\hline BPDA-II' ${ }_{\mathbf{a}}^{\prime}(\mathbf{H})$ & 65.9 & -11.7 & 94.2 & & 424 & 38 \\
\hline $\operatorname{DSDA}^{-\mathbf{I I}_{\mathbf{a}}^{\prime}}(\mathbf{H})$ & 60.1 & -11.8 & 94.8 & & 417 & 54 \\
\hline ODPA-II' ${ }_{\mathbf{a}}^{\prime}(\mathbf{H})$ & 30.4 & -7.6 & 85.0 & & 387 & 50 \\
\hline
\end{tabular}

${ }^{a} \mathrm{~L}^{*}$ is lightness. A positive $\mathrm{a}^{*}$ means red color, while a negative $\mathrm{a}^{*}$ indicated green color. A positive $b^{*}$ means yellow color, while a negative $b^{*}$ implies blue color. ${ }^{b}(\mathrm{H})$ : Poly(ether imide)s were obtained by thermal imidization method. (C): Poly(ether imide)s were obtained by chemical imidization with DMAc as solvent.

(3.01-3.65 at $1 \mathrm{MHz}$ ) were lower than the analogous nonfluorinated IV series (3.40-3.73 at $1 \mathrm{MHz})$. Both two series showed lower dielectric constants than the common polyimide, Kapton ${ }^{\circledR}$, because the dianhydride moieties contained the hexafluoropropane and ether group. The III series showed lower dielectric constants might be attributable to the presence of bulky $\mathrm{CF}_{3}$ group, which resulted in less efficient chain packing and increased free volume. In addition, the strong electronegativity of fluorine resulted in very low polarizability of the $\mathrm{C}-\mathrm{F}$ bonds, thereby decreasing the dielectric constant. III $_{\mathbf{a}-\mathrm{g}}$ also exhibited lower moisture absorptions $(0.09-0.44 \%)$ as a result of the hydrophobicity of the $\mathrm{CF}_{3}$ group than $\mathbf{I V}_{\mathbf{a - g}}$. Moreover, $\mathbf{I I I}_{\mathbf{f}}$ and $\mathbf{I V}_{\mathbf{f}}$ exhibited the lowest moisture in the two series because of contained the higher $\mathrm{CF}_{3}$ group in the repeat unit.

\section{CONCLUSIONS}

Two series of poly(ether imide)s III and IV are synthesized from the bis(ether anhydride) (I) with various aromatic diamines $\left(\mathbf{I I}_{\mathbf{a}-\mathbf{g}}\right)$ bearing the pendent trifluoromethyl group or non-fluorinated diamines $\left(\mathbf{I I}^{\prime}{ }_{\mathbf{a}-\mathbf{g}}\right)$ via chemical or thermal imidization. The III series is a kind of colorless polymer films and shows lighter col- 
Table V. Tensile properties of poly(ether imide) films

\begin{tabular}{ccccc}
\hline Polymer $^{\text {a }}$ & $\begin{array}{c}\text { Strength } \\
\text { at Yield } \\
(\mathrm{MPa})\end{array}$ & $\begin{array}{c}\text { Strength } \\
\text { at Break } \\
(\mathrm{MPa})\end{array}$ & $\begin{array}{c}\text { Elongation } \\
\text { at Break } \\
(\%)\end{array}$ & $\begin{array}{c}\text { Initial } \\
\text { Modulus } \\
(\mathrm{GPa})\end{array}$ \\
\hline $\mathbf{I I I}_{\mathbf{a}}$ & - & 102 & 11 & 1.7 \\
$\mathbf{I I I}_{\mathbf{b}}$ & - & 82 & 5 & 2.1 \\
$\mathbf{I I I}_{\mathbf{c}}$ & - & 83 & 10 & 1.7 \\
$\mathbf{I I I}_{\mathbf{d}}$ & - & 78 & 8 & 1.6 \\
$\mathbf{I I I}_{\mathbf{e}}$ & - & 93 & 12 & 1.6 \\
$\mathbf{I I I}_{\mathbf{f}}$ & - & 98 & 15 & 1.5 \\
$\mathbf{I I I}_{\mathbf{g}}$ & - & 91 & 12 & 1.6 \\
& & & & \\
$\mathbf{I V}_{\mathbf{a}}$ & - & 84 & 9 & 1.8 \\
$\mathbf{I V}_{\mathbf{b}}$ & - & 88 & 8 & 1.8 \\
$\mathbf{I V}_{\mathbf{c}}$ & - & 101 & 11 & 1.9 \\
$\mathbf{I V}_{\mathbf{d}}$ & - & 77 & 9 & 1.6 \\
$\mathbf{I V}_{\mathbf{e}}$ & 96 & 81 & 10 & 2.0 \\
$\mathbf{I V}_{\mathbf{f}}$ & 100 & 86 & 12 & 1.9 \\
$\mathbf{I V}_{\mathbf{g}}$ & - & 87 & 8 & 1.8 \\
\hline
\end{tabular}

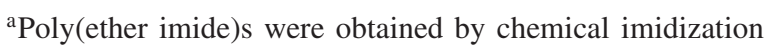
method with DMAc as solvent.
Table VI. Thermal behavior data of poly(ether imide)s

\begin{tabular}{|c|c|c|c|c|}
\hline \multirow{3}{*}{ Polymer ${ }^{\mathrm{a}}$} & \multirow{3}{*}{$\begin{array}{c}\text { DSC } \\
T_{\mathrm{g}}{ }^{\mathrm{b}}\left({ }^{\circ} \mathrm{C}\right)\end{array}$} & \multicolumn{3}{|c|}{ TGA } \\
\hline & & \multicolumn{2}{|c|}{ Decomposition $\mathrm{Temp}^{\mathrm{c}}\left({ }^{\circ} \mathrm{C}\right)$} & \multirow{2}{*}{$\begin{array}{c}\text { Char Yield } \\
\text { (wt \%) }\end{array}$} \\
\hline & & In Air & In Nitrogen & \\
\hline III $_{\mathbf{a}}$ & 199 & 553 & 556 & 49 \\
\hline III $_{b}$ & 201 & 550 & 549 & 50 \\
\hline III $_{c}$ & 205 & 554 & 559 & 55 \\
\hline III $_{d}$ & 263 & 492 & 495 & 53 \\
\hline III $_{e}$ & 199 & 537 & 539 & 56 \\
\hline III $_{\mathbf{f}}$ & 196 & 538 & 541 & 51 \\
\hline III $_{\mathrm{g}}$ & 239 & 558 & 567 & 57 \\
\hline $\mathbf{I V}_{\mathbf{a}}$ & 216 & 555 & 557 & 56 \\
\hline $\mathbf{I} \mathbf{V}_{\mathbf{b}}$ & 201 & 550 & 551 & 53 \\
\hline $\mathbf{I V}_{\mathbf{c}}$ & 228 & 556 & 562 & 60 \\
\hline $\mathbf{I V} \mathbf{V}_{\mathbf{d}}$ & 265 & 522 & 507 & 56 \\
\hline $\mathbf{I V}_{\mathrm{e}}$ & 209 & 546 & 545 & 56 \\
\hline$I_{\mathbf{f}}$ & 215 & 547 & 548 & 54 \\
\hline $\mathbf{I V}_{\mathrm{g}}$ & 258 & 558 & 564 & 62 \\
\hline
\end{tabular}

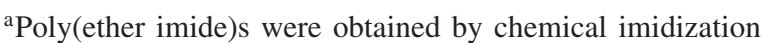
method with DMAc as solvent. ${ }^{\mathrm{b}}$ Baseline shift in the second heating DSC traces, with a heating rate of $15^{\circ} \mathrm{C} / \mathrm{min}$. ${ }^{\mathrm{c}} \mathrm{Tem}-$ peratures at which $10 \%$ weight loss were recorded by TG at a heating rate of $20^{\circ} \mathrm{C} / \mathrm{min} .{ }^{\mathrm{d}}$ Residual weight (\%) when heated to $800^{\circ} \mathrm{C}$ in nitrogen.

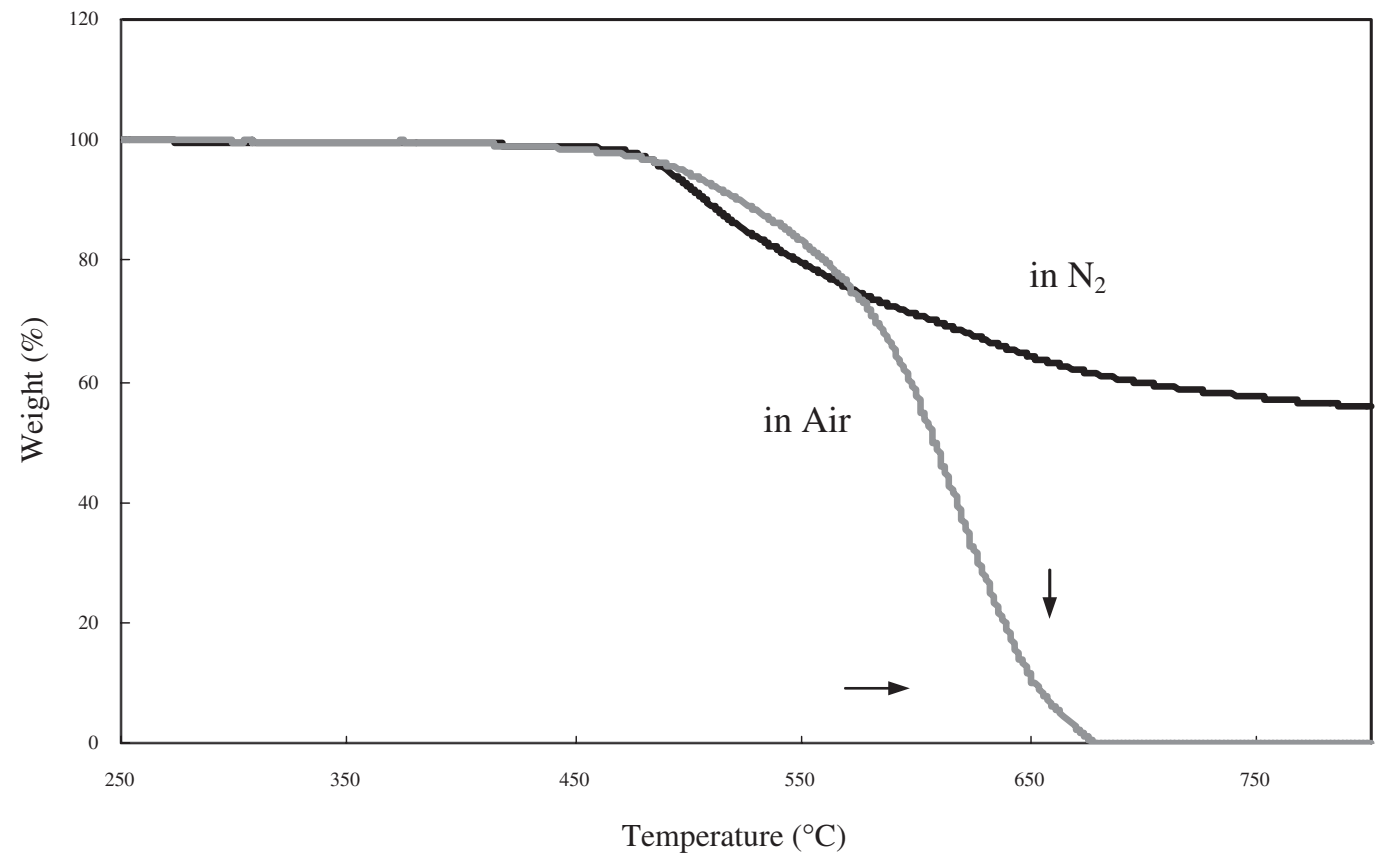

Figure 5. Typical TGA curves of poly(ether imide) $\mathbf{I V}_{\mathbf{d}}$ with a heating rate of $20^{\circ} \mathrm{C} / \mathrm{min}$.

or and greater transparence than the analogous nonfluorinated IV series. Moreover, the IV series shows lighter color than the common polyimide $\mathbf{V}$ series. In addition, the III series shows excellent solubility in the organic solvents at a concentration of $5-10 \%$. The solubility of IV series was lower than the III ser- ies but IV series could be dissolved in the most of testing solvents. This exhibits that these two series possess good solubility. The III series are also characteristics of good mechanical properties and thermal properties together with lower dielectric constants and moisture absorptions. 
C.-P. YANG, Y.-Y. SU, and M.-Y. HsU

Table VII. Moisture absorption and dielectric constants of poly(ether imide)s

\begin{tabular}{ccccccc}
\hline \multirow{2}{*}{ Polymer $^{\mathbf{a}}$} & $\begin{array}{c}\text { Film thickness } \\
(\mu \mathrm{m})\end{array}$ & $\begin{array}{c}\text { Moisture Absorption } \\
(\%)\end{array}$ & \multicolumn{4}{c}{ Dielectric Constant $^{\mathrm{b}}$} \\
\cline { 4 - 6 } & 61 & 0.15 & 3.27 & 3.25 & 3.20 & 3.23 \\
$\mathbf{I I I}_{\mathbf{a}}$ & 107 & 0.20 & 3.74 & 3.70 & 3.65 & 3.67 \\
$\mathbf{I I I}_{\mathbf{b}}$ & 65 & 0.21 & 3.33 & 3.29 & 3.24 & 3.26 \\
$\mathbf{I I I}_{\mathbf{c}}$ & 50 & 0.18 & 3.12 & 3.04 & 3.01 & 3.05 \\
$\mathbf{I I I}_{\mathbf{d}}$ & 105 & 0.12 & 3.56 & 3.51 & 3.45 & 3.47 \\
$\mathbf{I I I}_{\mathbf{e}}$ & 71 & 0.09 & 3.14 & 3.08 & 3.04 & 3.07 \\
$\mathbf{I I I}_{\mathbf{f}}$ & 76 & 0.44 & 3.45 & 3.35 & 3.30 & 3.33 \\
$\mathbf{I I I}_{\mathbf{g}}$ & & & & & & \\
& & 0.30 & 3.68 & 3.66 & 3.63 & 3.65 \\
$\mathbf{I V}_{\mathbf{a}}$ & 39 & 0.34 & 3.73 & 3.71 & 3.64 & 3.71 \\
$\mathbf{I V}_{\mathbf{b}}$ & 62 & 0.43 & 3.78 & 3.75 & 3.70 & 3.72 \\
$\mathbf{I V}_{\mathbf{c}}$ & 50 & 0.47 & 3.74 & 3.67 & 3.63 & 3.65 \\
$\mathbf{I V}_{\mathbf{d}}$ & 46 & 0.86 & 3.48 & 3.45 & 3.40 & 3.43 \\
$\mathbf{I V}_{\mathbf{e}}$ & 45 & 0.26 & 3.69 & 3.64 & 3.59 & 3.62 \\
$\mathbf{I V}_{\mathbf{f}}$ & 58 & 1.37 & 3.83 & 3.78 & 3.73 & 3.75 \\
$\mathbf{I V}_{\mathbf{g}}$ & 58 & & & & & \\
$\mathbf{K a p t o n}^{\mathbf{b}}$ & & 0.42 & 3.89 & 3.85 & 3.80 & 3.75 \\
\hline
\end{tabular}

${ }^{\text {a }}$ Poly(ether imide)s were obtained by the chemical imidization with DMAc as solvent. ${ }^{\mathrm{b}} \mathrm{A}$ reference polyimide (Kapton) prepared from PMDA and 4,4'-oxydianiline ( $\eta_{\text {inh }}$ of the poly (amic acid) precursor $1.90 \mathrm{dL} / \mathrm{g}$ ).

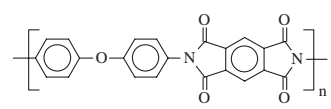

Acknowledgment. The authors are grateful to the National Science Council of the Republic of China for the financial support of this work (NSC 94-2216E-036-014).

\section{REFERENCES}

1. M. J. M. Adadie and B. Sillion, "Polyimides and other High-Temperature Polymers," Elsevier Science Publishers, Amsterdam, 1991.

2. "Polyimide: Synthesis, Characterization, and Application, Vol. I \& II,” K. L. Mittal, Ed., Plemnum, New York, 1984.

3. S. Tamai, M. Ohta, S. Kawashima, H. Oikawa, K. Ohkoshi, and A. Yamaguchi, Eur. Patent 234882 (1987).

4. S. Ando, T. Sawada, and Y. Inoue, Electron. Lett., 29, 2143 (1993).

5. C. Feger, M. M. Khojasteh, and J. E. McGrath, Ed., "Polyimides: Chemistry and Characterization," Elsevier, Amsterdam, 1994.

6. K. Yamanaka, M. Jikei, and M. Kakimoto, Macromolecules, 34, 3910 (2001).

7. C. P. Yang, H. C. Chiang, and Y. Y. Su, Polym. J., 36, 979 (2004).

8. H. S. Kim, Y. H. Kim, S. H. Ahn, and S. K. Kwon, Macromolecules, 36, 2327 (2003).

9. R. A. Dinc-Hart and W. W. Wright, Makromol. Chem., 143, 189 (1971).

10. F. E. Rogers, U.S. Patent 3,356,648 (1964).

11. C. P. Yang, S. H. Hsiao, and M. F. Hsu, J. Polym. Sci., Part A: Polym. Chem., 40, 524 (2002).

12. C. S. Wang and R. W. Yang, J. Appl. Polym. Sci., 66, 609 (1997).

13. C. P. Yang and S. Yy, Polymer, 44, 6311 (2003).

14. C. P. Yang, R. S. Chen, and K. H. Chen, J. Polym. Sci., Part
A: Polym. Chem., 41, 922 (2003).

15. S. H. Hsiao and C. Yu, Polym. J., 29, 944 (1997).

16. D. H. Lee, S. Y. Koo, D. Y. Kim, and H. J. Choi, J. Appl. Polym. Sci., 76, 249 (2000).

17. M. W. Kim, D. K. Ahn, D. H. Lee, L. S. Park, K. H. Seo, K. R. Ha, and W. S. Kim, Polymer (Korea), 28(4), 314 (2004).

18. "Polyimides: fundamentals and applications," M. K. Ghosh and K. L. Mittal, Ed., Marcel Dekker, New York, 1996.

19. K. Takashi, S. Atsushi, and T. Shoji, Jpn. Kokai Tokkyo Koho JP 297,067 (2000).

20. K. Xie, J. G. Liu, H. W. Zhou, S. Y. Zhang, M. H. He, and S. Y. Yang, Polymer, 42, 7267 (2001).

21. S. Banerjee, M. K. Madhra, A. K. Salunke, and G. Maier, J. Polym. Sci., Part A: Polym. Chem., 40, 1016 (2002).

22. B. Y. Myung, J. J. Kim, and T. H. Yoon, J. Polym. Sci., Part A: Polym. Chem., 40, 4217 (2002).

23. C. P. Yang and H. W. Yang, U.S. Patent 6,093,790 (2000).

24. K. Xie, S. Y. Zhang, J. G. Liu, M. H. He, and S. Y. Yang, J. Polym. Sci., Part A: Polym. Chem., 39, 2581 (2001).

25. C. P. Yang, R. S. Chen, and H. C. Chiang, Polym. J., 35, 662 (2003).

26. C. P. Yang, S. H. Hsiao, and K. H. Chen, Polymer, 43, 5095 (2002).

27. C. P. Yang, R. S. Chen, and K. H. Chen, J. Appl. Polym. Sci., 95, 922 (2005).

28. C. P. Yang, R. S. Chen, and K. H. Chen, J. Polym. Sci., Part A: Polym. Chem., 41, 922 (2003).

29. C. P. Yang and H. C. Chiang, Colloid Polym. Sci., 282, 1347 (2004).

30. C. P. Yang and J. J. Cherng, J. Polym. Sci., Part A: Polym. Chem., 33, 2209 (1995).

31. S. H. Hsiao, C. P. Yang, and C. K. Lin, J. Polym. Res., 2, 1 (1995).

32. F. Li, S. Fang, J. J. Ge, P. S. Honigfort, J. C. Chen, F. W. Harris, and S. Z. D. Cheng, Polymer, 40, 4571 (1999). 